\title{
Obesity, Fat Mass and Immune System: Role for Leptin
}

\author{
Vera Francisco ${ }^{1 *}$, Jesús Pino ${ }^{1 \dagger}$, Victor Campos-Cabaleiro ${ }^{1}$, Clara Ruiz-Fernández ${ }^{1}$, \\ Antonio Mera², Miguel A. Gonzalez-Gay³, Rodolfo Gómez ${ }^{4}$ and Oreste Gualillo ${ }^{1}$
}

\begin{abstract}
'The NEIRID Group (Neuroendocrine Interactions in Rheumatology and Inflammatory Diseases), Servizo Galego de Saude and Instituto de Investigación Sanitaria de Santiago, Santiago University Clinical Hospital, Santiago de Compostela, Spain, ${ }^{2}$ Servizo Galego de Saude, Division of Rheumatology, Santiago University Clinical Hospital, Santiago de Compostela, Spain, ${ }^{3}$ Epidemiology, Genetics and Atherosclerosis Research Group on Systemic Inflammatory Diseases, Hospital Universitario Marqués de Valdecilla, Universidad de Cantabria and IDIVAL, Santander, Spain, ${ }^{4}$ Musculoskeletal Pathology Group, Servizo Galego de Saude and Instituto de Investigación Sanitaria de Santiago, Santiago University Clinical Hospital, Santiago de Compostela, Spain
\end{abstract}

\section{OPEN ACCESS}

Edited by:

Joaquin Garcia-Estañ,

Universidad de Murcia, Spain

Reviewed by:

Deanne Helena Hryciw,

Griffith University, Australia Antonio La Cava

University of California, Los Angeles,

United States

Giuseppe Matarese,

Università degli Studi di Napoli

Federico II, Italy

*Correspondence:

Vera Francisco

vlgfrancisco@gmail.com

tThese authors have contributed equally to the realization of this work.

Specialty section:

This article was submitted to

Integrative Physiology,

a section of the journal

Frontiers in Physiology

Received: 18 December 2017

Accepted: 11 May 2018

Published: 01 June 2018

Citation:

Francisco V, Pino J,

Campos-Cabaleiro V,

Ruiz-Fernández C, Mera A,

Gonzalez-Gay MA, Gómez R and Gualillo O (2018) Obesity, Fat Mass and Immune System: Role for Leptin.

Front. Physiol. 9:640.

doi: 10.3389/fphys.2018.00640
Obesity is an epidemic disease characterized by chronic low-grade inflammation associated with a dysfunctional fat mass. Adipose tissue is now considered an extremely active endocrine organ that secretes cytokine-like hormones, called adipokines, either pro- or anti-inflammatory factors bridging metabolism to the immune system. Leptin is historically one of most relevant adipokines, with important physiological roles in the central control of energy metabolism and in the regulation of metabolism-immune system interplay, being a cornerstone of the emerging field of immunometabolism. Indeed, leptin receptor is expressed throughout the immune system and leptin has been shown to regulate both innate and adaptive immune responses. This review discusses the latest data regarding the role of leptin as a mediator of immune system and metabolism, with particular emphasis on its effects on obesity-associated metabolic disorders and autoimmune and/or inflammatory rheumatic diseases.

Keywords: adipokines, adipose tissue, immunometabolism, leptin, metabolism, rheumatic diseases, rheumatoid arthritis, Type 2 diabetes mellitus (T2DM)

Abbreviations: ADAMTS, a disintegrin and metalloproteinase with thrombospondin motifs; AMPK, adenosine monophosphate-activated protein kinase; Arg-1, arginase-1; BMDM, bone marrow-derived macrophages; BMI, body mass index; cAMP, cyclic adenosine monophosphate; CCL, CC-chemokine ligand; CD, cluster of differentiation; COX-2, cyclooxygenase-2; CPCs, chondrogenic progenitor cells; CRP, C-reactive protein; DAMPs, damage-associated molecular patterns; DCs, dendritic cells; ERK, extracellular signal-regulated kinase; GLUT, glucose transporter; HFD, high-fat diet; HLA-DR, human leukocyte antigen-antigen D related; HSC, hepatic stellate cell; ICAM, intercellular adhesion molecule; IFN $\gamma$, interferon $\gamma$; IL, interleukin; iNOS, inducible nitric oxide synthase; IPFP, intrapatellar fat pad; IRS, insulin receptor substrate; JAK, Janus kinase; JNK, c-jun N-terminal kinase; KC, kupffer cells; LEPR, leptin receptor; LPL, lipoprotein lipase; LPS, lipopolysaccharide; MAPK, mitogen-activated protein kinase; MCP-1, monocyte chemoattractant protein 1; MEK, mitogen-activated protein kinase kinase; MIP- $1 \alpha$, macrophage inflammatory protein-1 alpha; miRNA, microRNA; MMPs, matrix metalloproteinases; NAFLD, non-alcoholic liver disease; NASH, non-alcoholic steatohepatitis; NF- $\mathrm{kB}$, nuclear factorкB; NO, nitric oxide; NOS2, nitric oxide synthase 2; OA, osteoarthritis; PAMPs, pathogen-associated molecular patterns; PGE2, prostaglandin E2; PI3K, phosphoinositide 3-kinase; PKC, protein kinase C; PMA, phorbol myristate acetate; PMNs, human polymorphonuclear neutrophils; $\operatorname{PPAR} \alpha$, peroxisome proliferator-activated receptor alpha; RA, rheumatoid arthritis; ROR $\gamma$ t, retinoic acid-related orphan receptor gamma t; ROS, reactive oxygen species; SLE, systemic lupus erythematosus; SREBP-1c, sterol regulatory element-binding protein-1c; STAT, signal transducer and activator of transcription; T2DM, type 2 diabetes mellitus; TGF- $\beta$, transforming growth factor; Th, T helper cells; TLR, toll-like receptor; TNF- $\alpha$, tumour necrosis factor- $\alpha$; Treg, T regulatory cells; VAT, visceral adipose tissue; VCAM, vascular cell adhesion molecule; WAT, white adipose tissue. 


\section{INTRODUCTION}

Obesity, the greater public health problem in the western world, is associated with high-incident chronic autoimmune and inflammatory pathologies, such as T2DM, NAFLD, OA, and RA, thus having a huge social and economic impact (Zhang et al., 2014). Adipose tissue, initially considered as a simple energy storage tissue, is now recognized as an active endocrine organ and a bona fide immune organ, constituted not only by adipocytes but also by fibroblasts, endothelial cells and a wide array of immune cells (adipose tissue macrophages, neutrophils, mast cells, eosinophils, $\mathrm{T}$ and $\mathrm{B}$ cells that maintains tissue homeostasis in lean individuals (Huh et al., 2014; Vieira-Potter, 2014). The adipocyte expansion caused by positive energy balance leads to adipocyte hypoxia, apoptosis, and cell stress, ultimately resulting in the expression of chemoattractant molecules and infiltration of inflammatory cells (Vieira-Potter, 2014). The obese adipose tissue is also characterized by a markedly deregulated production of adipose tissue-derived factors, i.e., adipokines, a growing family of low molecular weight, biologically active proteins with pleiotropic functions (Al-Suhaimi and Shehzad, 2013). Adipokines are crucial players not only in energy metabolism but also in inflammation and immunity, most of them being increased in obesity and contributing to the associated 'low-grade inflammatory state' (Tilg and Moschen, 2006).

Leptin was discovered in 1994 by the group of Jeffrey Friedman (Zhang et al., 1994) and is the best-characterized member of adipokine family. Encoded by LEP gene (the human homolog of murine $o b$ gene), leptin is a $16 \mathrm{kDa}$ non-glycosylated protein mainly produced by adipocytes, but also by skeletal muscle, intestine, brain, joint tissues and bone (Scotece et al., 2014). This adipokine exerts its physiological activity through its receptor (LEPR or Ob-R), a class I cytokine receptor family from diabetes $(d b)$ gene (Münzberg and Morrison, 2015). There are at least six LEPR isoforms that differ in the length of the cytoplasmic domain: a soluble isoform, four short isoforms, and a long isoform, which has the full intracellular domain that allows the transduction of leptin signal via JAK and STAT signaling pathways (Frühbeck, 2006). Alternatively to canonical JAK/STAT pathway, LEPR could activate ERK 1/2, p38 MAPK, JNK, PKC, and PI3K/Akt pathways (Zhou and Rui, 2014) (Figure 1). This hormone, together with other regulatory molecules, has a central role in appetite and body weight homeostasis by inducing anorexigenic factors (as cocaine-amphetaminerelated transcript) and suppressing orexigenic neuropeptides (as neuropeptide Y) on hypothalamus (Al-Suhaimi and Shehzad, 2013; Rosenbaum and Leibel, 2014). Therefore, central leptin resistance, caused by impairment of leptin transportation, leptin signaling and leptin target neural circuits, is considered the main risk factor for the obesity pathogenesis.(Al-Suhaimi and Shehzad, 2013; Rosenbaum and Leibel, 2014). Interestingly, leptin release is modulated in a circadian rhythm manner, which has been correlated with sweet taste recognition (Nakamura et al., 2008). Moreover, leptin also affects other physiological functions, namely bone metabolism, inflammation, infection and immune responses (Scotece et al., 2014) (Figure 2). Accordingly, LEPR is expressed in across the cells of innate and adaptive immune system, evoking leptin as a crucial linker of neuroendocrine and immune systems (Carlton et al., 2012; Procaccini et al., 2017).

This review summarizes the latest data regarding the role of leptin as a mediator of innate and adaptive immune cells activity, and its effects on obesity-associated metabolic disorders, namely T2DM and NAFLD, and autoimmune and/or inflammatory rheumatic diseases, such as OA and RA.

\section{LEPTIN AND IMMUNOMETABOLISM}

The rising prevalence of obesity in western society is paralleled with a significant augment in autoimmune diseases. Accordingly, numerous association studies had demonstrated that overweight is implicated in a higher risk of developing multiple sclerosis (Kavak et al., 2015), RA (Ajeganova et al., 2013), and psoriasis (Duarte et al., 2013). On the other hand, malnutrition/starvation has been long related to increased susceptibility to infectious diseases (Taylor et al., 2013; Jones et al., 2014). These observations bring out immune response as a highly energy-dependent biological process that is dependent on an adequate food intake and metabolism. In fact, a recent article critically discuss the correlation between autoimmunity and overnutrition or metabolic pressure (De Rosa et al., 2017). At the interface of the historically distinct fields of immunology and metabolism, immunometabolism has emerged as a new research discipline (Mathis and Shoelson, 2011). In the last years, it has been evidenced that metabolic status of immune cells directly determines their function and differentiation, thus affecting immunity and tolerance, as well as the failure of the immune response in autoimmune pathologies (Gaber et al., 2017). In fact, innate and adaptive immune cells adapt to altered tissue microenvironment, characterized by hypoxia and nutrient competition, by reprogramming their metabolism (Gaber et al., 2017), and failure in this metabolic reconfiguration ultimately leads to a deregulated immune response and pathology (Gaber et al., 2017).

Leptin, the forerunner of adipokine family, is a key sensor of energy metabolism and a cornerstone in the regulation of metabolism-immune system interplay. Malnutrition results in hypoleptinemia, while obesity leads to hyperleptinemia, both conditions affecting the immune response in an opposite manner. In particular, obese subjects demonstrated decreased levels of Treg (central players in the control of peripheral immune tolerance), which are inversely correlated with leptin levels and BMI (Matarese et al., 2010). In malnutrition, altered $T$ cell function and metabolism was associated with decreased leptin levels (Cohen et al., 2017). Leptin and LepR-deficient mouse models presented augmented number and activity of Treg cells together with a resistance to autoimmune diseases, and leptin replacement rescues Treg cell levels to wild-type mice values (Matarese et al., 2010). Accordingly, human T cell activation and production of cytokines can be induced after incubation with $10 \mathrm{ng} / \mathrm{mL}$ exogenous leptin following nutritional rehabilitation (Rodríguez et al., 2007). Furthermore, the central effect of leptin on the hypothalamus is mediated, at least in part, by inhibition of hypothalamic-pituitary-adrenal axis and activation of the 


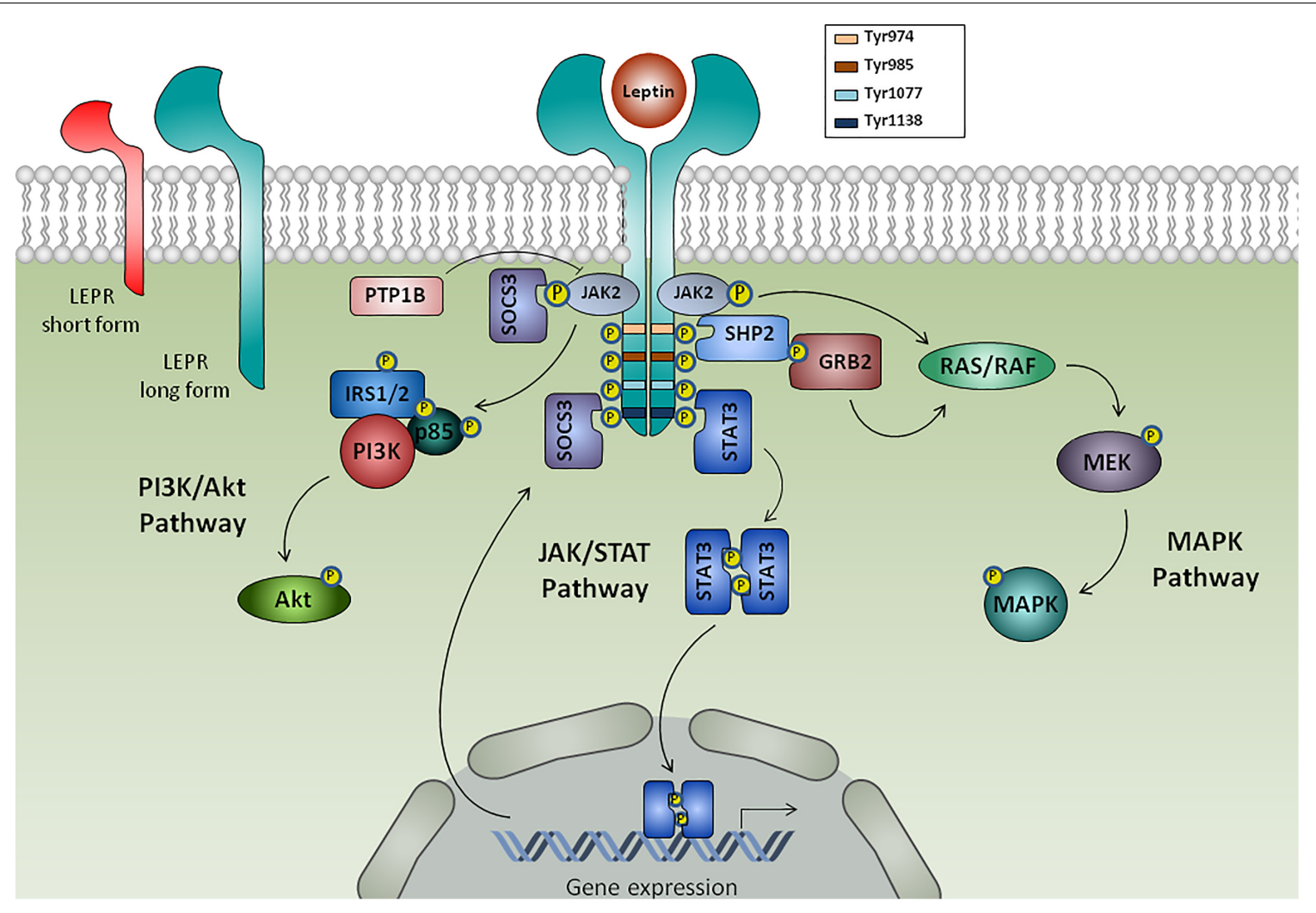

FIGURE 1 | Leptin receptors and intracellular leptin signaling pathways. Leptin binds to its receptor (LEPR) isoforms: the soluble isoform (not shown), the short isoform and the long isoform. Binding of leptin to the long form of LEPR results in its dimerization and prompts Janus kinase 2 (JAK2) autophosphorylation, which phosphorylates cytoplasmatic domain of LEPR in tyrosine residues (Tyr974, Tyr985, Tyr1077, Tyr1138), each one functioning as docking sites for cytoplasmic adaptors. LEPR-phosphorylated Tyr1138 mediates the interaction with signaling transducer and activator of transcription 3 (STAT3), which dimerize and translocate to the nucleus to activate gene transcription of target genes, such as suppressor of cytokine signaling 3 (SOCS3) that acts as a negative feedback signaling. Additionally, leptin induces the activation of SHP2, which then recruits the adaptor protein Grb2 to prompt activation of Ras/Raf/MAPK signaling cascade. Leptin also mediated phosphatidylinositol-3-kinase (PI3K)/Akt activation via insulin receptor substrate 1/2 (IRS1/2) and protein tyrosine phosphatase 1B (PTP1B) acts as a negative regulator of leptin signaling through JAK2 dephosphorylation.

sympatho-adrenal axis, having the sympathetic nervous system a function in the central control of the immune system (PérezPérez et al., 2017). Moreover, most immune cells express LEPR at their surface, which evokes a straight action of leptin in the modulation of the immune response (Procaccini et al., 2017).

\section{LEPTIN AND INNATE IMMUNITY (FIGURE 3)}

\section{Granulocytes (Neutrophils, Eosinophils, and Basophils)}

Human polymorphonuclear neutrophils express LEPR (CaldefieChezet et al., 2001), but only the short-form (Ob-Ra) was been detected (Zarkesh-Esfahani et al., 2004). Although the short-form of LEPR lacks most of the intracellular domain of the receptor, it is enough to signal through MAPK pathways, enhancing CD $11 \mathrm{~b}$ expression and preventing apoptosis, but not through JAKSTAT pathways as long-form of LEPR (Bjorbaek et al., 1997; Zarkesh-Esfahani et al., 2004). Leptin is likely to act as a survival cytokine for neutrophils. At $500 \mathrm{nM}$, leptin delayed the cleavage of Bid and Bax, mitochondrial release of cytochrome $\mathrm{C}$ and second mitochondria-derived activator of caspase, as well as the activation of caspase- 3 and caspase- 8 (Bruno et al., 2005). PI3K, $\mathrm{NF}-\kappa \mathrm{B}$, and MAPK pathways were involved in the anti-apoptotic activity of leptin in human neutrophils in vitro (Bruno et al., 2005; Sun et al., 2013). Additionally, leptin (250 ng/ml) stimulated the release of oxygen radicals, such as superoxide anion and hydrogen peroxide, by PMNs (Caldefie-Chezet et al., 2001, 2003).

There is strong evidence for an effect of leptin on neutrophil chemotaxis and infiltration. Leptin $(50 \mathrm{ng} / \mathrm{ml})$ mediated the migration of human neutrophils in vitro, through activation of p38 MAPK and Src kinases (Montecucco et al., 2006), and by indirect mechanisms via TNF- $\alpha$ released by monocytes (CaldefieChezet et al., 2001; Zarkesh-Esfahani et al., 2004), having no secretagogue properties (no detectable $\left[\mathrm{Ca}^{2+}\right] \mathrm{i}$ mobilization, oxidant production, or $\beta 2$-integrin upregulation) (Montecucco et al., 2006). Otherwise, leptin inhibits neutrophil chemotaxis to classical chemoattractants, like interleukin (IL)-8 (Montecucco et al., 2006). Murine neutrophils with Q223R LEPR mutation had reduced chemotaxis toward leptin (Naylor et al., 2014), while 


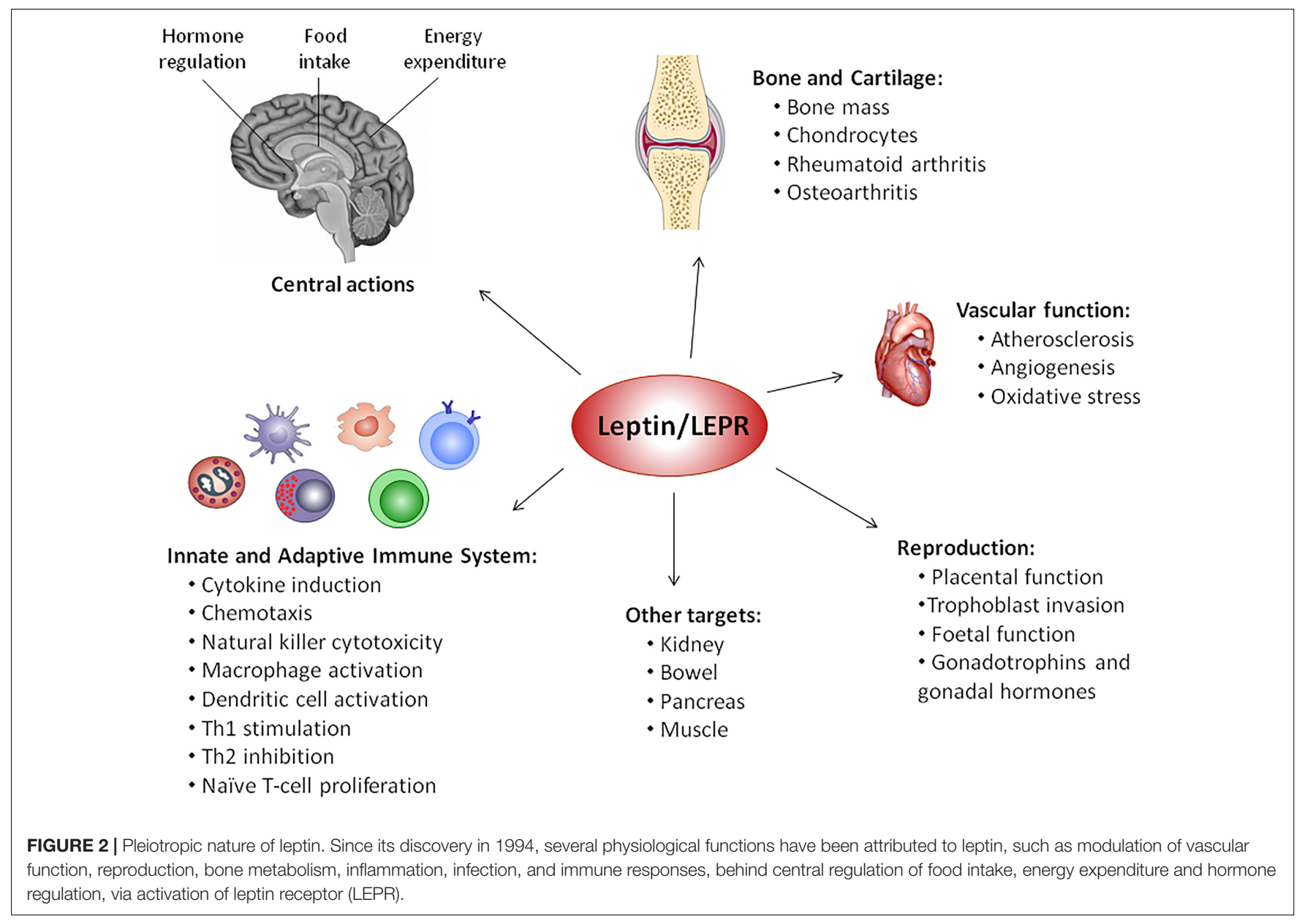

neutrophils from human volunteers and wild-type C57BL/6 mice migrated toward leptin in a dose-dependent manner, requiring JAK2/PI3K signaling (Ubags et al., 2014). Nevertheless, one study found that physiological concentrations of leptin $(1-100 \mathrm{ng} / \mathrm{ml})$ do not affect human neutrophils, and high leptin concentrations induced survival and changes in neutrophils proteome, but no effect on chemotaxis was observed (Kamp et al., 2013). In vivo studies clarified the effect of leptin in neutrophils. It was observed that neutrophil populations were enhanced in rats with high-fat-diet induced obesity, compared with control diet rats (do Carmo et al., 2013), and neutrophils from obese subjects displayed elevated superoxide release and chemotactic activity (Brotfain et al., 2015). Furthermore, leptin administration (50 $\mu \mathrm{g}$ ) increased pulmonary neutrophilia in Escherichia coli pneumonia murine model as well as in healthy mice (Ubags et al., 2014).

Alike neutrophils, both human eosinophils and basophils expressed LEPR on the cell surface (Bruno et al., 2005; Suzukawa et al., 2011). In eosinophils, leptin $(50 \mathrm{ng} / \mathrm{ml})$ enhanced the release of pro-inflammatory cytokines IL-1 $\beta$ and IL-6, and chemokines IL- 8 , growth-related oncogene- $\alpha$ and MCP-1 (Wong et al., 2007). It also modulated the surface expression of adhesion molecules; in particular, up-regulates ICAM-1 and CD18, and suppress ICAM-3 and L-selectin (Wong et al., 2007). Treatment of human eosinophils with recombinant leptin in vitro delayed apoptosis via JAK, NF- $\kappa \mathrm{B}$, and p38 MAPK signaling pathways, suggesting leptin as a survival cytokine (Wong et al., 2007), similar to neutrophils (Bruno et al., 2005). Furthermore, leptin also stimulated chemokinesis (Wong et al., 2007) and enhanced chemotactic migration of eosinophils isolated from human peripheral blood, in a dose-dependent manner, however, the underlying mechanisms remain unclear (Kato et al., 2011). In obese individuals, eosinophils demonstrated greater adhesion and chemotaxis toward eotaxin and RANTES (CCL5), compared with non-obese healthy volunteers (Grotta et al., 2013).

In human basophils, leptin treatment $(10 \mathrm{nM})$ induced a strong migratory response, promoted the secretion of type 2 cytokines IL-4 and IL-13, and up-regulated the cell surface expression of CD63, which may have an exacerbating action on allergic inflammation (Suzukawa et al., 2011). Moreover, leptin is a survival-enhancing factor of human basophils, as aforementioned for eosinophils and neutrophils. Although leptin was a weak effect on direct induction of basophil degranulation, it potently primed basophils for enhanced degranulation in response to aggregation of IgE or its high-affinity receptor FceRI (Suzukawa et al., 2011).

Altogether, these findings suggest leptin as a potent activator of neutrophils, eosinophils, and basophils through its positive action in cell survival, cytokines release and chemotaxis. 


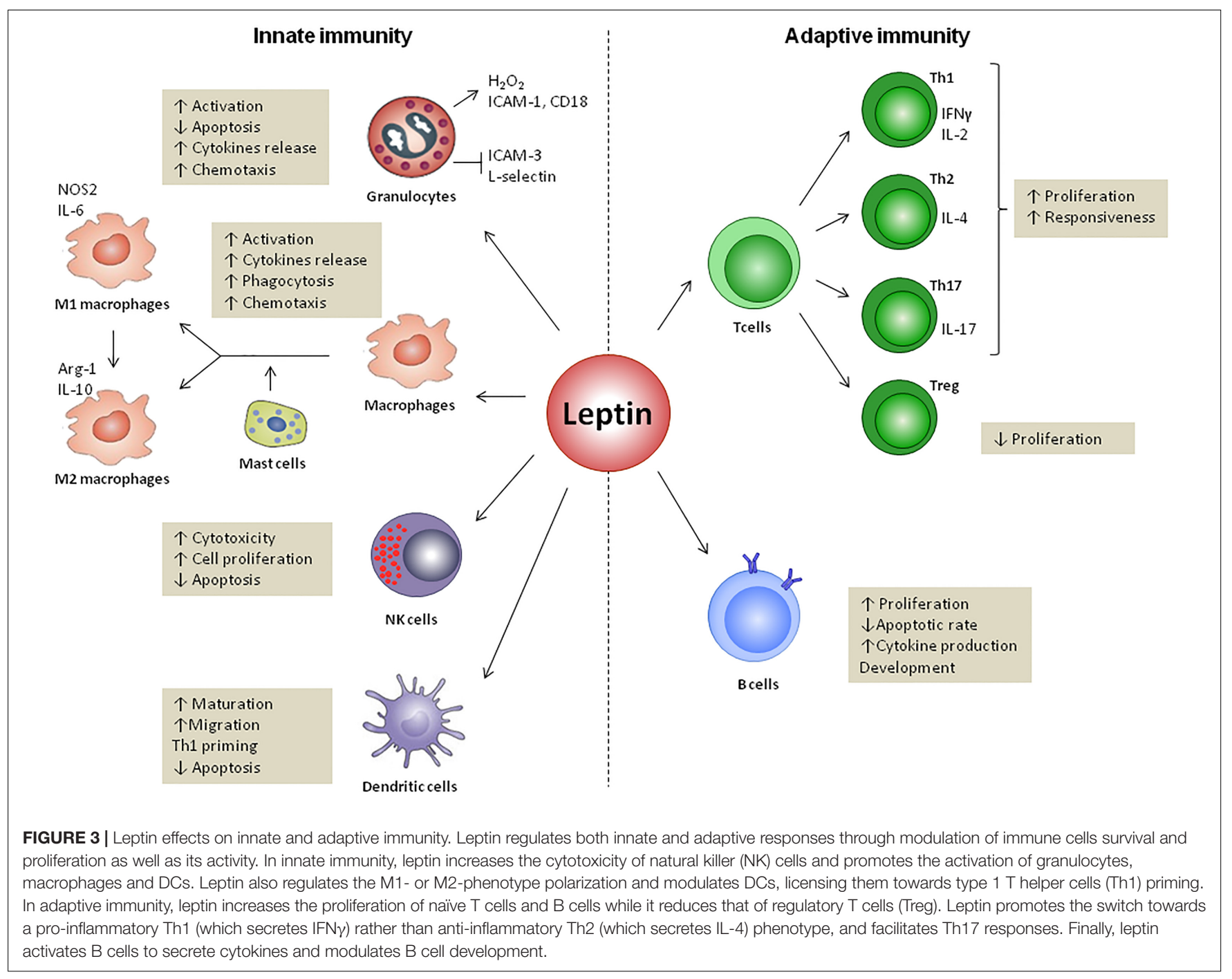

\section{Monocytes and Macrophages}

Both isoforms of LEPR are expressed in PBMCs, being lower in cells from obese individuals compared with lean subjects (Tsiotra et al., 2000). Functional LEPR was also expressed in macrophages (O'Rourke et al., 2001). The effect of leptin on monocytes and macrophages has been well-established since its first evidence in Santos-Alvarez et al. (1999). Leptin promoted the proliferation of human circulating monocytes in vitro as well as its activation through induction of TNF- $\alpha$ and IL-6 production, and stimulation of surface markers, namely CD25, HLA-DR, CD38, CD71, CD11b, CD11c, and CD16 (SantosAlvarez et al., 1999; Cannon et al., 2014). Moreover, leptin potentiated the stimulatory effect of LPS or PMA on human monocytes (Santos-Alvarez et al., 1999), and increased CCLs in cultured murine macrophages, being JAK2-STAT3 signaling pathway involved (Kiguchi et al., 2009). Leptin (625 nM) also augmented the production of several inflammatory mediators in monocytes/macrophages, such as interleukin 1 receptor antagonist (IL-1Ra) (Gabay et al., 2001), interferon-c-inducible protein (Meier et al., 2003), leukotrienes (Mancuso, 2004), nitric oxide (Dixit et al., 2003), and pro-inflammatory cytokines, namely TNF- $\alpha$, IL-6, IL-1 $\beta$, and resistin (Tsiotra et al., 2013; Scotece et al., 2014; Inzaugarat et al., 2017). By contrast, it was reported that $1 \mu \mathrm{g} / \mathrm{ml}$ leptin had no effect on IL-1 $\beta$ secretion but enhanced IL-18 in the THP-1 murine monocytic cell line. These apparent discrepancies could be species-specific (human vs. murine cells) and/or leptin treatment-dependent $(1 \mu \mathrm{g} / \mathrm{ml}$ for $24 \mathrm{~h}$ vs. $1 \mu \mathrm{g} / \mathrm{ml}$ for $3 \mathrm{~h}$ ). Additionally, recombinant leptin increased the expression of TLR2, but not TLR4, in human monocytes (Jaedicke et al., 2013).

A dose-dependent effect of leptin as a trophic factor to prevent apoptosis was found in serum-deprived human monocytes, being this effect mediated by the p42/p44 MAPK pathways (Najib and Sánchez-Margalet, 2002). Leptin (2 nM) stimulated the oxidative burst in monocytes (Sánchez-Pozo et al., 2003), and increased LPL expression through oxidative stress- and PKC-dependent pathways (Maingrette and Renier, 2003). Moreover, leptin promoted the phagocytosis of apoptotic cells by macrophages from lupus mice, via modulation of cAMP levels (Amarilyo et al., 2014). Leptin also promoted a 
defensive environment against Leishmania donovani infection by induction of macrophage phagocytic activity and intracellular ROS generation (Dayakar et al., 2016). Accordingly, macrophages from knocked-out LepR Tyr 985 mice presented reduced phagocytosis and killing activity of Klebsiella pneumoniae that was associated with diminished ROS production (Mancuso et al., 2012). It has been demonstrated that leptin-mediated protein radical formation, tyrosine nitration and activation of $\mathrm{KCs}$ are caused by peroxynitrite formation, which exacerbated NASH in diet-induced obese mice (Chatterjee et al., 2013). Concerning to chemoattractive activity, it was verified that leptin induced in vitro chemotactic responses for monocytes and macrophages (Curat et al., 2004; Gruen et al., 2007), via intracellular calcium influx, JAK/STAT, MAPK and PI3K pathways (Gruen et al., 2007). However, it has been reported that hematopoietic LEPR deficiency in mice did not change macrophage accumulation in WAT after diet-induced obesity versus wild-type mice (Gutierrez and Hasty, 2012). Likely, compensatory in vivo effects of other cytokines (like IL-1 or TNF- $\alpha$ ) present in WAT could occur in obese individuals and which are absent in in vitro assays.

Leptin treatment $(50 \mathrm{ng} / \mathrm{ml})$ of human macrophages in culture, induced 'alternatively activated' or M2-phenotype surface markers, but they were able to secrete M1-typical cytokines (TNF- $\alpha$, IL-6, IL-1 $\beta$, IL-1ra, IL-10, MCP-1, and macrophage inflammatory protein 1-alpha (MIP-1 $\alpha)$ ), suggesting a role for leptin in the phenotype of macrophages found in adipose tissue (Acedo et al., 2013).In macrophages, leptin also triggered catecholamine-dependent increases in cAMP-histone deacetylase 4 signaling pathway, that reduced inflammation in adipose tissue (Luan et al., 2014). Additionally, leptin increased the expression of LEPR in M2 macrophages and stimulated IL- 8 expression via p38 and ERK signaling pathways (Cao et al., 2016). In tumor-associated macrophages, leptin induced the expression of IL-18 via $\mathrm{NF}-\mathrm{kB}$, possible contributing to tumor progression ( $\mathrm{Li} \mathrm{K}$. et al., 2016).

Macrophages are indirectly regulated by leptin through mast cells (Zhou et al., 2015). In particular, leptin expression was reduced in both human and mouse mast cells from lean adipose tissue compared with obese individuals. Leptin deficiency led to the anti-inflammatory activity of mast cells and, consequently, to a shift in macrophage polarization from $\mathrm{M} 1$ to $\mathrm{M} 2$; in vitro co-cultures of mast cells with BMDM increased IL-4-mediated arginase-1 and IL-10 expression, and suppressed LPS-mediated iNOS and IL-6 expression (Zhou et al., 2015). Furthermore, reduction of mast cells in leptin-deficient $o b / o b$ mice exacerbated obesity and diabetes, indicating an important role of mast cells in obesity-related inflammation through its reactivity to leptin levels (Zhou et al., 2015).

Biologic drugs used for the treatment of psoriatic arthritis, namely adalimumab (an anti-TNF- $\alpha$ monoclonal antibody) and ustekinumab (a monoclonal antibody against the p40 subunit of IL-12 and IL-23), augmented LEPR expression in THP-1 human macrophages (Voloshyna et al., 2016). However, only ustekinumab was able to increase the expression of leptin, suggesting a novel mechanism for this biological drug. Further mechanistic studies focused on the leptin pathway could have potential therapeutic action in common obesity-related complications of psoriasis (Voloshyna et al., 2016). The establishment of LepR-deficient macrophage cell line DB-1, derived from differentiated bone marrow cells of Lepr-knockout mice, provide a powerful tool to study the role of leptin and its receptor in obesity-associated inflammation and immune system deregulation (Dib et al., 2016).

\section{NK Cells}

The role of leptin in regulating NK cell development and activation was first verified in obese Lepr-deficient $(d b / d b)$ mice, which showed decreased NK cell function (Tian et al., 2002). In this animal model, the population of NK cells in bone marrow was impaired through an increase in apoptotic rate, and recombinant leptin $(200 \mathrm{ng} / \mathrm{ml})$ significantly enhanced the survival of immature NK cells from wild-type mice via modulation of Bcl-2 and Bax gene expression (Lo et al., 2009). Furthermore, leptin administration $(500 \mu \mathrm{g} / \mathrm{kg})$ led to a higher activity of NK cells in lean animals (Nave et al., 2008). Consistently, human NK cells expressed functional long- and short-form of LEPR that influenced NK cell cytotoxicity through STAT3 activation and, consequently, transcription of genes encoding IL-2 and perforin (Zhao et al., 2003).

The above-mentioned results indicated that leptin signaling is required for normal NK cell immune function. However, there are some controversial findings concerning the time of leptin treatment in vitro. Short-term stimulation of human NK cells with leptin $(50 \mathrm{nM})$ raised the secretion of IFN $\gamma$ and cytotoxicity (Wrann et al., 2012; Laue et al., 2015). By contrast, long-term exposure to leptin decreased NK cell proliferation and immune function (Wrann et al., 2012). Obesity is partially characterized by a state of long-term, highly elevated leptin exposure, and NK cells from obese animals were significantly resistant to leptin stimulation (Nave et al., 2008), which could explain the functional desensitization of $\mathrm{NK}$ cells after long-term exposure. Accordingly, exposure of NK-92 human cell line to hyperleptinemia (similar to that observed in obese individuals) led to metabolic activation of NK-92 cells after $24 \mathrm{~h}$, but there is a reduction of cell metabolism after $96 \mathrm{~h}$ (Lamas et al., 2013). Furthermore, obese individuals have lower NK function compared to lean individuals (Laue et al., 2015) and, after weight loss, the decrease of plasma leptin levels is accompanied by a restoration of IFN $\gamma$ production by NK cell (Jahn et al., 2015; Bähr et al., 2017; Favreau et al., 2017).

Overall, leptin signaling seems to be necessary for normal NK cell immune function, increasing the immune activity and cell proliferation, and reducing the apoptotic rate of NK cells. Long-term exposure to hyperleptinemia, observed in obesity, has been associated with decreased NK immune activity possibly due to the development of leptin resistance. Further studies are needed to better understand the correlation between leptin levels 
and NK cell development and function, as well as the potential implications in obesity.

\section{Dendritic Cells}

Human DCs, both immature and mature DCs, present functional active LEPR with the capacity to signal STAT-3 phosphorylation (Mattioli et al., 2009). Leptin (10 nM) acted as an activator of human DCs, evidenced by up-regulation of IL-1 $\beta$, IL-6, IL-12, TNF- $\alpha$ and MIP- $1 \alpha$ production, improvement of immature DCs migration (Mattioli et al., 2008; Al-Hassi et al., 2013) and their chemotactic responsiveness, licensing them toward Th1 priming (Mattioli et al., 2008). Moreover, leptin treatment promoted DC survival through decreased apoptosis via activation of NF- $\kappa \mathrm{B}$ and PI3K-Akt signaling pathways, with a parallel increase of bcl-2 and bcl- $x_{L}$ gene expression (Lam et al., 2006; Mattioli et al., 2009).

Lepr-deficient $d b / d b$ mouse bone marrow culture displayed a reduced number of DCs, attributable to dysregulation of Bcl2 genes and a consequent increase of apoptosis (Lam et al., 2006). Moreover, DCs from $d b / d b$ mice possessed markedly reduced expression of co-stimulatory molecules and a Th 2-type cytokine profile, with a poor capacity to stimulate allogeneic T cell proliferation (Lam et al., 2006). Consistently, $d b / d b$ DCs demonstrated down-regulation of PI3K/Akt and STAT-3 pathways (Lam et al., 2006). Lep-deficient ob/ob mice presented a reduced expression of DC maturation markers (CD40, CD80, and CD86), decreased production of inflammatory cytokines (IL-12, TNF- $\alpha$, and IL-6), and augmented TGF- $\beta$ production, but $o b / o b$ mice-derived DCs were more efficient in inducing Treg or Th17 cells than wild-type animals (MoraesVieira et al., 2014). In DCs from ob/ob mice, leptin deficiency resulted in defective antigen presentation function toward Leishmania donovani, which was not reversed by leptin treatment (Maurya et al., 2016). Conversely, one report verified no changes in the phenotype, activation, antigen processing or presentation of DCs from leptin-knockout mice, but these cells showed an enhanced ability to activate $\mathrm{T}$ cells, suggesting that leptin may dampen T-cell responsiveness in the physiological context (Ramirez and Garza, 2014). Diet-induced obesity in mice fed with HFD results in an elevation of serum leptin levels and splenic CD11c ${ }^{+}$DCs, with diminished DC cell stimulatory capacity, being these effects distinct from that caused by HFD alone in obese-resistant mice (Boi et al., 2016).

Altogether, these data demonstrated the important role of leptin in DC activation, chemoattraction, and survival, with possible implications in DC maturation and migration. Given the ability of DCs to orchestrate immune response and promote potent immunogenic responses through activation of $\mathrm{T}$ cell immunity, DCs-based immunotherapies to elicit immunity against cancer and infectious diseases are currently being developed. In particular, DCs can be differentiated ex vivo, exposed to antigens and induced to mature in the presence of adjuvants. Then, the mature DCs are injected into the patient and migrate to the lymph nodes to present antigens to T cells. Thus, the modulation of DCs maturation and activity by leptin is of most importance considering a potential application of leptin in immunotherapeutic approaches and as novel adjuvant immunopotentiator in vaccination protocols employing ex vivo generated autologous DCs.

\section{LEPTIN AND ADAPTIVE IMMUNITY (FIGURE 3)}

The role of leptin in adaptive immunity has first evidenced working with $o b / o b$ and $d b / d b$ mice, which showed thymus atrophy, T-cell lymphopenia, and impaired delayed-type hypersensibility (Lord et al., 1998; Howard et al., 1999; Matarese, 2000). Moreover, chronic leptin administration ( $1 \mu \mathrm{g} / \mathrm{g}$ body weight) reversed immunosuppressive status and thymic atrophy of ob/ob mice (Lord et al., 1998, Nature; Howard et al., 1999, J. Clin. Inv.). Since then, the role of leptin in $\mathrm{T}$ and $\mathrm{B}$ cell populations have been extensively studied.

\section{T Cells}

$\mathrm{T}$ lymphocytes expressed the long form of LEPR (higher in peripheral $\mathrm{CD} 4+$ than in CD8+ $\mathrm{T}$ cells) (Lord et al., 1998; Kim et al., 2010), with signaling capacity to activate JAK-STAT pathway (Sanchez-Margalet and Martin-Romero, 2001). Consequently, leptin modulated cell proliferation, responsiveness, and polarization of $\mathrm{T}$ cells. Leptin dosedependently promoted the proliferation of human naïve $(\mathrm{CD} 45 \mathrm{RA}+) \mathrm{CD} 4+\mathrm{T}$ cells, whereas it minimally affected memory (CD45RO+) CD4+ T cells proliferation (Lord et al., 1998, 2002). Additionally, morbidly obese children, who were congenitally deficient in leptin, presented a decreased number of circulating CD4 $+\mathrm{T}$ cells, as well as impaired $\mathrm{T}$ cell proliferation and cytokine release, which were reversed by administration of recombinant human leptin (Farooqi et al., 2002). Moreover, leptin inhibited autophagy in human CD4+CD25- conventional T cells via mTOR pathway (Cassano et al., 2014), which emerged as the potential link between immunity and nutritional status (Procaccini et al., 2012).

\section{T Helper Cells}

Leptin also promoted CD4 $+\mathrm{T}$ cell polarization toward a Th1 response (which secretes IFN $\gamma$ and IL-2) rather than Th2 response (which secretes IL-4) (Martín-Romero et al., 2000). Accordingly, under Th2-polarizing conditions, the in vitro leptin treatment decreased IL-4-producing $\mathrm{T}$ cells and inhibited $\mathrm{T}$ cell proliferation (Batra et al., 2010). However, it was recently reported that in vivo leptin-deficiency attenuated allergic airway inflammation and that high leptin levels associated with obesity promoted proliferation and survival of Th2 lymphocytes, as well as the production of type 2 cytokines, altogether contributing to allergic responses (Zheng et al., 2016). Besides that, leptin was involved in thymus morphology and functions (Lamas et al., 2016), particularly in thymocyte differentiation of double positive CD4+CD8+ T cells into single positive CD4+ T cells (Kim et al., 2010).

IL-17-producing Th cells (Th17) have a crucial role in the promotion and maintenance of inflammatory and autoimmune pathologies. Leptin was demonstrated to increase Th17 population and responsiveness in SLE, via retinoic acid-related 
orphan receptor (ROR) $\gamma \mathrm{t}$ (Yu et al., 2013; Fujita et al., 2014; Reis et al., 2015). In collagen-induced arthritis mouse model, articular injection of leptin $(5 \mu \mathrm{g})$ increased the number of Th17 in the joint tissue, resulting in exacerbating joint inflammation, and consequently early onset of arthritis and increased disease severity (Deng et al., 2012). Leptin, in concentrations similar to that found in blood during pregnancy, promoted the differentiation of peripheral blood CD4+ cells to Th17 cells, but suppressed the formation of Treg cells in vitro (Orlova and Shirshev, 2014). CD4+ $\mathrm{T}$ cell-derived leptin, but not plasma leptin, were positively correlated with the percentage of Th17 cells or ROR $\gamma$ t levels in chronic lymphocytic thyroiditis, an organ-specific autoimmune disease (Wang et al., 2013). Furthermore, Lepr-deficient CD4+ T cells verified a reduced capacity for Th17 differentiation, via down-regulation of STAT3 activation (Reis et al., 2015).

\section{T Regulatory Cells (Treg)}

Leptin also regulated CD4+CD25+ Treg proliferation (Matarese et al., 2010). Treg lymphocytes play a critical role in controlling the inappropriate immune responses characteristic of autoimmune diseases and allergy. In humans, leptin negatively affected the proliferation of Foxp3+CD4+CD25+ Treg; in vitro leptin neutralization, during anti-CD3 and anti-CD28 stimulation, led to the proliferation of the isolated human Treg cell (De Rosa et al., 2007). Obese individuals presented a reduced number of CD4+CD25+CD127-Foxp3+ Treg cells, which was correlated with body weight, BMI, and plasma leptin levels (Wagner et al., 2013). Moreover, leptin-deficient mice presented an increased percentage of peripheral Treg, compared with wild-type mice, which is reversed after leptin administration (De Rosa et al., 2007). It was verified that leptin played an important role in Treg dysfunction in patients with pulmonary arterial hypertension (Huertas et al., 2016). Accordingly, Lepr-deficient rats developed less severe hypoxiainduced pulmonary hypertension and were protected against decreased Treg function after exposure to hypoxia (Huertas et al., 2016). In SLE, the disease-associated higher leptin serum levels were negatively correlated with disease severity and number of Treg cells (Ma et al., 2015; Margiotta et al., 2016; Wang et al., 2017), and fasting-induced hypoleptinaemia was related to Treg population recovery in lupus-prone mice (Liu et al., 2012). Leptin-deficient $o b / o b$ mice and a mouse model of lupus with leptin deficiency demonstrated increased frequency of Tregs cells (Fujita et al., 2014; Lourenço et al., 2016). These data evidenced the potential of anti-leptin-based approaches for immune system-dysregulated pathologies associated with reduced Treg function, such as SLE, obesity, T2DM, and metabolic syndrome.

$\mathrm{T}$ cell metabolism is directly related to its function (MacIver et al., 2013); effector T cells, such as Th1 and Th17, demand a high glycolytic metabolism to fuel proliferation and function, while Treg cells require oxidative metabolism to fuel suppressive activity. Recently, leptin was found to directly promote T-cell glycolytic metabolism and consequently induce Th17 cell differentiation, being Treg cells unchanged, in a mouse model of experimental autoimmune encephalomyelitis (Gerriets et al.,
2016). Leptin regulated glucose metabolism partly by upregulation of glucose transporter Glut1 (Saucillo et al., 2014). Moreover, fasting led to decreased ability of $\mathrm{T}$ cells to secrete IL-2 and IFN $\gamma$, and inability to up-regulate glucose uptake and glycolytic flux (Saucillo et al., 2014), while Treg expansion was increased (Liu et al., 2012); leptin administration (1 $\mu \mathrm{g} / \mathrm{g}$ body weight) rescued peripheral $\mathrm{T}$ cell function and metabolism in fasted mice (Saucillo et al., 2014). Likely, fasting was extensively reported to be associated with immune deficiency and increased susceptibility to infection (Gerriets and MacIver, 2014). Thus, leptin seems to provide a key link between nutritional status and inflammatory T cell responses (Gerriets et al., 2016; De Rosa et al., 2017).

Altogether, these data revealed the ability of leptin to increase immune activity by modulation of $\mathrm{T}$ cell number and function. Leptin can promote proliferation of naive T cells, as well as Th1 and Th17 proliferation and cytokine production. Moreover, leptin decreases Treg cell proliferation. Considering the regulatory effects of leptin on Th17 and Treg populations, revoking leptin signaling might be a potential therapeutic approach for inflammation and autoimmunity.

\section{B Cells}

In contrast to macrophages and $\mathrm{T}$ cells, little is known about the role of leptin in the B lymphocytes development and function. $B$ cells expressed the long form of the LEPR, suggesting a direct effect of leptin on B cell function (Busso et al., 2002). Accordingly, $d b / d b$ and $o b / o b$ presented a reduced number of peripheral blood and bone marrow B lymphocytes, which was recovered after leptin treatment (Bennett et al., 1996; Claycombe et al., 2008). Conversely, $d b / d b$ mice presented an increased absolute number of B cells in the peritoneal cavity (Jennbacken et al., 2013), and the increase of leptin was correlated with a decrease in B cells of mice with unbalanced diets (carbohydraterich and fat-rich) (Martínez-Carrillo et al., 2015). Thus, further investigation is needed to better clarify the role of leptin in lymphopoiesis. Leptin promoted B cell homeostasis through inhibition of apoptosis and induction of cell cycle entry via Bcl-2 and cyclin D1 activation (Lam et al., 2010). Furthermore, leptin dose-dependently activated human peripheral blood B cells, inducing the secretion of pro-inflammatory cytokines, namely TNF- $\alpha$ and IL- 6 , and the anti-inflammatory cytokine IL-10, via JAK-STAT and p38MAPK-ERK1/2 signaling pathways (Agrawal et al., 2011). Likewise, leptin (50 $\mathrm{ng} / \mathrm{ml})$ activated and induced the production of higher amounts of TNF- $\alpha$, IL- 6 , and IL- 10 by B cells from aged subjects compared to young individuals (Gupta et al., 2013), which is associated with leptin-mediated STAT3 phosphorylation (Gupta et al., 2013; Frasca et al., 2016).

Leptin can also modulate B cell development - decrease pro$B$, pre- $B$ and immature $B$ cells and increase mature $B$ cellsin bone marrow of fasted mice, characterized by low serum leptin levels (Tanaka et al., 2011). Leptin administration reversed the starvation-induced lymphopenia of bone marrow B cells, indicating an important role of central leptin in the immune system (Tanaka et al., 2011; Fujita et al., 2012). Moreover, leptin might regulate B cell activity in obesity (Nikolajczyk, 2010; Frasca et al., 2016). In particular, B cells were described to 
accumulate in murine VAT and to critically regulate T2DMassociated inflammation through activation of CD8+ and Th1 cells and release of pathogenic antibodies (Winer et al., 2011; DeFuria et al., 2013).

In summary, leptin can increase $B$ cell population by augmenting proliferation and reducing the apoptotic rate, activate $\mathrm{B}$ cell to secrete pro-, anti- and regulatory cytokines, and also modulate B cell development.

\section{LEPTIN AND IMMUNE-METABOLIC PATHOLOGIES}

\section{Leptin and Obesity-Associated Metabolic Disorders}

Obesity is associated with life-threatening co-morbidities, including insulin resistance, T2DM, NAFLD and steatohepatitis (NASH) (Lebovitz, 2003; Kamada et al., 2008; Klöting and Blüher, 2014; Fasshauer and Blüher, 2015). Adipokines, in particular leptin, mediate the crosstalk between adipose tissue and metabolic organs (especially liver, muscle, pancreas and central nervous system) (Cao, 2014). Thus, leptin has emerged as a significant pathological component in the development of metabolic disorders (DePaoli, 2014).

\section{Type 2 Diabetes Mellitus}

T2DM is the most significant obesity-associated metabolic disorder and their prevalence is increasing worldwide in parallel (Bhupathiraju and $\mathrm{Hu}, 2016$ ). Leptin has been proposed as a therapeutic target of T2DM, for its impact on food intake and body weight as well as its potential to improve insulin action (Kalra, 2009). Interestingly, leptin-deficient mice (Pelleymounter et al., 1995) and human (Farooqi et al., 1999, 2002; Ozata et al., 1999) have diabetic features, which were reversed with leptin replacement. The anti-diabetic effect of leptin is mediated by activation of IRS-PI3K pathway that improved insulin sensitivity in peripheral tissues (Morton et al., 2005). Activation of JAK2/IRS/PI3K/Akt signaling pathway by leptin and insulin triggers the translocation of glucose transporter type 4 (GLUT4) from cytosol to cell surface, and glucose uptake (Benomar et al., 2006; Zhao and Keating, 2007). Moreover, in the liver, leptin deficiencies decrease AMPK activity (Namkoong et al., 2005), which is also involved in glucose homeostasis regulation (Schultze et al., 2012). Leptin has also been implicated in the regulation of insulin secretion by pancreatic $\beta$-cells (Kulkarni et al., 1997), as well as in peripheral insulin resistance (Silha et al., 2003; Yadav et al., 2011). However, clinical trials to evaluate the potential of leptin monotherapy in obese humans with T2DM failed to demonstrate therapeutic activity acutely or chronically, with no observation of important weight loss or metabolic improvements (insulin sensitization, amelioration of glucose and lipid metabolism) (Mittendorfer et al., 2011; Moon et al., 2011; Wolsk et al., 2011). In this context, unresponsiveness to leptin - leptin resistance, caused by hyperleptinemia observed in obese humans, should be considered (Frederich et al., 1995). Further understanding of leptin resistance mechanisms could enable new leptin targeted therapies for obesity and diabetes in specific subsets of patients. In fact, leptin therapy improved the diabetic condition in children (Farooqi et al., 1999, 2002) and adults (Licinio et al., 2004) with familial leptin deficiency, and in lipoatrophic diabetes (Oral et al., 2002).

Importantly, T2DM is associated with altered components of immune system, including modified levels of specific chemokines and cytokines, changed number and activation status of leukocytes populations and increased apoptosis and tissue fibrosis (Donath, 2014), all promoted by obesity-associated inflammation in adipose tissue (Donath and Shoelson, 2011). Given the modulator action of leptin in innate and adaptive immune system (deeply described above), it is rational to see leptin as a linker of T2DM development, not only with metabolism but also with inflammation. Indeed, in patients with newly diagnosed T2DM, leptin levels were correlated with CRP, an inflammatory marker broadly evaluated for its association with risk factors for T2DM pathology (Morteza et al., 2013).

\section{Non-alcoholic Fatty Liver Disease}

NAFLD, the major cause of chronic liver illness in developed countries, comprises a wide group of pathologies primary caused by a buildup of fat in the liver that spans from simple steatosis to NASH, liver fibrosis, cirrhosis, and hepatocellular carcinoma (Tiniakos et al., 2010). Given that NAFLD is increasing worldwide and it is associated with high-incident extra-hepatic complications such as obesity, T2DM, cardiovascular diseases and chronic kidney disease (Byrne and Targher, 2015; Polyzos et al., 2015), great efforts have been made in the last years to unravel the mechanisms underlying the disease pathophysiology and further development of effective NAFLD therapies.

Hepatic inflammation and hepatocyte injury and death are hallmarks of NAFLD/NASH. Fat overload by hepatocytes causes lipotoxicity and the release of DAMPs which activated Kupfer cells (KC; specialized liver macrophages) and HSC promoting inflammation and fibrosis, respectively. $\mathrm{KC}$ activation plays a central role in NAFLD pathophysiology through the production of pro-inflammatory cytokines and chemokines such as TNF- $\alpha$, IL-1 $\beta$, IL-6, CCL2 and CCL5, that contributed to leukocyte infiltration and inflammatory necrosis of hepatocytes, and fibrogenesis (Arrese et al., 2016). Dysbiosis of the gut microbiota may also conduct to KC activation through PAMPs, which originate in the gut and reach liver via portal circulation due to altered intestinal permeability. Other immune cells have been implicated in the NAFLD pathophysiology, although its role is less clear (Arrese et al., 2016). NK cells were impaired in experimental $\mathrm{NASH}$, while natural killer $\mathrm{T}$ cells (unique immune cell subtype that expresses NK cells surface markers as well as T-cell antigen receptor) are depleted in steatosis but increased later during disease progression likely leading to inflammation and fibrosis in NASH via the production of IL-4, osteopontin, and IFN- $\gamma$ (Tajiri and Shimizu, 2012; Tian et al., 2013). Neutrophils exacerbate the ongoing inflammation through macrophage recruitment and cell damage via the release of myeloperoxidase, ROS, and elastase (Xu R. et al., 2014). The role of DCs in NASH is complex and somehow controversial. DCs rapidly infiltrate into the liver in experimental NASH exhibiting an activated immune phenotype, but its depletion exacerbates 
hepatic inflammation (Tacke and Yoneyama, 2013; Arrese et al., 2016). B- and T-cells also contributed to hepatic inflammation via secretion of pro-inflammatory cytokines that stimulated $\mathrm{KC}$ activation (Arrese et al., 2016).

Considering the strong metabolic and inflammatory components of NAFLD, leptin is regarded as a key regulator of NAFLD physiopathology (Polyzos et al., 2015). Leptin seems to feature a dual activity in NAFLD experimental models by exerting an early protective anti-steatosis effect in the initial stages of the disease, and a late pro-inflammatory and pro-fibrogenic action, when the disease persists or progress (Polyzos et al., 2015). In leptin-resistant Zucker fa/fa diabetic fatty rats, the expression of SREBP-1c (master regulator of glucose metabolism, and lipid and fatty acid production) is increased in liver (Kakuma et al., 2000), and infusion of adenovirus-leptin decreased hepatic triglyceride synthesis and $\beta$-oxidation via SREBP- $1 \mathrm{c}$ down-regulation and PPAR $\alpha$ up-regulation (Lee et al., 2002), thus preventing hepatic lipid accumulation.

Through anti-steatotic effect, leptin can ultimately lead to hepatic detrimental effects. Leptin activated HSCs, leading to up-regulation of pro-inflammatory and pro-angiogenic factors expression (like angiopoietin-1 and vascular endothelial growth factor), as well as collagen $\alpha 1$ and tissue inhibitor of metalloproteinase-1, ultimately acting as hepatic fibrogenesis inducer (Polyzos et al., 2015). Activated HSCs were able to secrete leptin, thus establishing a vicious cycle that further promotes liver fibrosis (Polyzos et al., 2015). Moreover, leptin was reported as potent HSCs mitogen and to prevent HSCs apoptosis, hence promoting the pathogenesis of hepatic fibrosis. Leptin $(200 \mathrm{nM})$ increased the expression of TGF- $\beta 1$ in KCs and sinusoidal endothelial cells, and connective tissue growth factor in KCs (Ikejima et al., 2002), being KCs-HSCs cross-talk proposed for liver fibrosis (Wang et al., 2009). Additionally, leptin is involved in macrophage-mediated KCs activation via induction of oxidative stress in macrophages (Chatterjee et al., 2013). Compared to healthy subjects, NAFLD patients demonstrated an increased leptin-stimulated $\mathrm{TNF} \alpha$ and ROS production in peripheral monocytes, as well as IFN $\gamma$ production in circulating CD $4+$ cells (a marker of Th1 differentiation) (Inzaugarat et al., 2017). Altogether, these data elucidated the role of leptin in NAFLD by modulation of HSCs, KCs, and inflammatory cells response.

In $o b / o b$ mice, the congenital absence of leptin abrogated the development of $\mathrm{CCl}_{4}$-induced hepatic fibrosis comparing to lean littermates, which is reverted by leptin treatment $(100 \mathrm{ng} / \mathrm{ml})$ (Saxena et al., 2002). Likewise, xenobiotics- or thioacetamideinduced hepatic fibrosis was prevented in Zucker fa/fa rats, being involved the activation of HSCs and expression of procollagenI and TGF- $\beta 1$ (Ikejima et al., 2005). In humans, the role of leptin is controversial. Although leptin serum levels were initially related with hepatic steatosis but not with necroinflammation or fibrosis (Chitturi et al., 2002), later studies failed to demonstrate any significant association (Tsochatzis et al., 2009). Recombinant leptin has been successfully used in the treatment of insulin resistance and hepatic steatosis in patients with lipodystrophy and NASH (Oral et al., 2002; Petersen et al., 2002; Javor et al., 2005). However, large-scale and well-designed prospective cohort studies are necessary to deeply elucidate the role of leptin in hepatic lipid handling, inflammation, and fibrosis along with the identification of NAFLD patients subsets that may benefit from therapies directed to leptin system.

\section{Leptin in Rheumatic Diseases}

Leptin has been described as a key factor in the pathophysiology of rheumatic diseases due to its capability to modulate bone and cartilage metabolism and to influence innate and adaptive immune responses (Figure 4).

\section{Osteoarthritis}

Osteoarthritis, the most common joint disease, is a painful and debilitating illness characterized by progressive degeneration of articular joints. Initially seen as simply "wear and tear" disease, OA is currently considered a complex and multifactorial pathology triggered by inflammatory and metabolic imbalances that affect the entire joint structure (articular cartilage, meniscus, ligaments, bone, and synovium) (Loeser et al., 2012). Leptin levels are increased in serum, infrapatellar fat pad (IPFP), synovial tissues, and cartilage of OA patients compared to healthy individuals (Dumond et al., 2003; de Boer et al., 2012; Conde et al., 2013). Accordingly, leptin-deficient or LepR-deficient mice developed extreme obese phenotype without increased incidence of knee OA, suggesting that leptin signaling is essential to the development and progression of obesity-associated OA (Griffin et al., 2009). Furthermore, long form of LEPR was found to be expressed in human cartilage cells - chondrocytes (Figenschau et al., 2001).

Some initial findings suggested an anabolic role of leptin in cartilage. In particular, exogenous leptin administration $(30 \mu \mathrm{g})$ stimulated proteoglycan and growth factors (insulin-like growth factor- 1 and TGF- $\beta$ ) synthesis in rat knee-joint cartilage (Dumond et al., 2003). However, most of the studies reported a catabolic role of leptin underlying OA pathogenesis. A recent study determining the gene expression profile of leptin-induced articular rat cartilage by microarray analysis, associated the upregulation of matrix metalloproteinases (MMPs), inflammatory factors, growth factors and osteogenic genes with leptin-induced OA phenotype (Fan et al., 2018). Our group demonstrated that leptin (400 or $800 \mathrm{nM}$ ), in synergy with IFN $\gamma$ or IL-1 $\beta$, activated type 2 nitric oxide synthase (NOS2) via JAK2, PI3K and MAPK (MEK1 and p38) pathways, in cultured human and murine chondrocytes (Otero et al., 2003, 2005, 2007). Nitric oxide (NO), is a well-known pro-inflammatory mediator which lead to joint degradation through induction of chondrocyte phenotype loss, apoptosis and metalloproteinase (MMP) activity (Rahmati et al., 2016). Leptin ( $800 \mathrm{nM})$, alone or in combination with IL- $1 \beta$, also induced the expression of COX-2 and the production of PGE2, IL-6, and IL-8 in cartilage explants of OA patients and human primary chondrocytes (Vuolteenaho et al., 2009; Gomez et al., 2011), revealing that leptin contributed to the pro-inflammatory environment of OA cartilage. It was also demonstrated that leptin $(500 \mathrm{ng} / \mathrm{ml})$ enhanced IL-6 production, mediated by chondrocyte-synovial fibroblast cross-talk, in OA patients (Pearson et al., 2017). Moreover, leptin modulated the production of inflammatory mediators by immune cells. In 


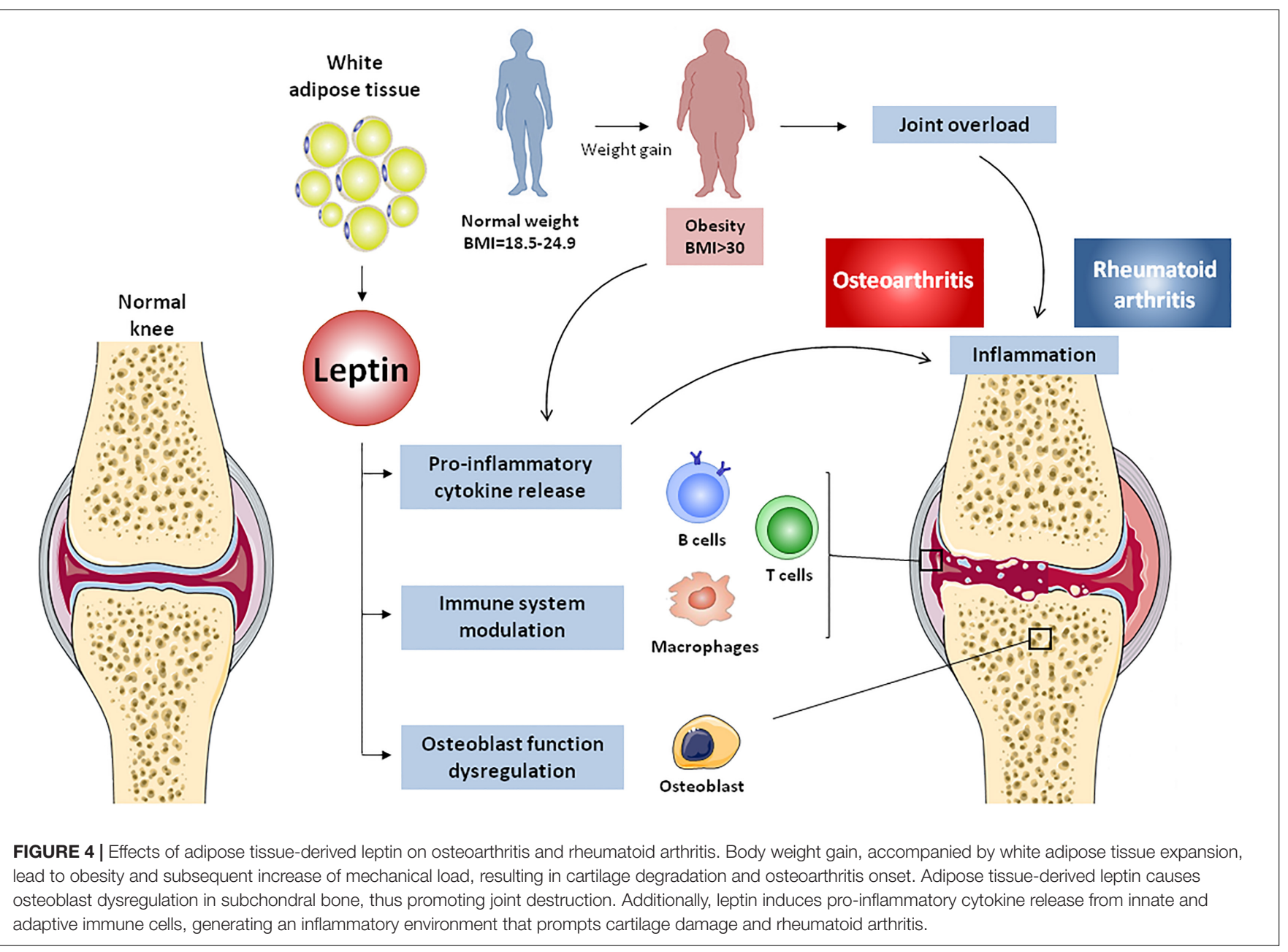

particular, the production of IL-6, IL-8, and CCL3 were increased by leptin in $\mathrm{CD} 4+\mathrm{T}$ cells from OA patients, but not from healthy subjects (Scotece et al., 2017); thus, demonstrating new insights into the role of leptin in the immune system and OA pathophysiology.

Leptin can directly induce the expression of MMPs that are involved in OA-related joint destruction, like MMP-1 (also known as interstitial collagenase), MMP-3 (also known as stromelysin), and MMP-13 (also known as collagenase), via NF$\kappa \mathrm{B}, \mathrm{PKC}$, and MAPK pathways (Bao et al., 2010; Koskinen et al., 2011; Hui et al., 2012). MMP-2 (72 kDa type IV collagenase), MMP-9, and disintegrin and metalloproteinase with thrombospondin motifs (ADAMTS) 4 and ADAMTS5, were also increased by leptin, while fibroblast growth factor 2 and proteoglycan were down-regulated (Bao et al., 2010; Conde et al., 2011b). Leptin ( $800 \mathrm{nM})$ can perpetuate the cartilagedegradation processes due to induction of VCAM-1, an adhesion molecule responsible for leukocyte and monocyte chemotaxis and infiltration to inflamed joints, via JAK2 and PI3K pathways in chondrocytes (Conde et al., 2012; Vestweber, 2015). SOCS-3 was pointed as a regulator of leptin-induced expression of MMP-1, -3, and -13 , and pro-inflammatory mediators IL-6, NO and COX-2 (Koskinen-kolasa et al., 2016). Additionally, leptin increased the production of other adipokines, namely lipocalin-2, by human cultured chondrocytes (Conde et al., 2011a).

MicroRNAs, small single-stranded non-coding segments of RNA, are increasingly recognized as regulatory molecules involved in disease processes, including OA, inflammation, and obesity (Marques-Rocha et al., 2015; Deiuliis, 2016; Nugent, 2016). miR-27 was found to be decreased in OA chondrocytes and to directly targeted the $3^{\prime}$ - untranslated region of leptin (Zhou et al., 2017). Furthermore, the injection of OA rats with miR27 lentiviral overexpression vector resulted in decreased levels of IL- 6 and -8, as well as MMP-9 and -13, thus indicating the protective action of miR-27 in OA, possibly by targeting leptin.

Chondrogenic progenitor cells as cartilage seed cells are crucial to maintain cartilage homeostasis and replace damaged tissue (Seol et al., 2012). Leptin (50 ng/ml) can reduce CPCs migratory ability and their chondrogenic potential, and augment CPCs osteogenic transformation, hence changing CPC differentiation fate (Zhao et al., 2016). CPC cell cycle arrest and senescence are also induced by leptin (Zhao et al., 2016). Furthermore, leptin influenced the regulation of bone metabolism through induction of abnormal osteoblast function, which is associated to joint destruction in OA patients (Findlay and Atkins, 2014; Conde et al., 2015). The augmented production 
of leptin by OA subchondral osteoblasts is related with in vitro elevated levels of alkaline phosphatase, osteocalcin, collagen type 1, and TGF- $\beta 1$, all being responsible for dysregulated osteoblast function (Mutabaruka et al., 2010). Additionally, bone morphogenic protein (BMP)-2 is increased in leptin-stimulated human primary chondrocytes (Chang et al., 2015). Leptin also suppressed bone formation in vivo (Ducy et al., 2000), but there are some discrepancies with in vitro results.

Taking together, this evidence indicated a key role of leptin in OA pathophysiology by influencing pro-inflammatory status, cartilage catabolic activity, as well as cartilage and bone remodeling. However, studies in a large cohort of patients are needed to better clarify the leptin significance in the development and progression of $\mathrm{OA}$.

\section{Rheumatoid Arthritis}

Rheumatoid arthritis is a chronic inflammatory joint illness characterized by synovial membrane inflammation and hyperplasia ("swelling"), production of autoantibodies, namely rheumatoid factor and anti-citrullinated protein antibody - autoimmune disease, destruction of cartilage and bone ("deformity"), and systemic features including skeletal, cardiovascular, pulmonary, and psychological complications (McInnes, 2011; Smolen et al., 2016). Evidencing the crucial role of immune system in RA pathology, RA-associated synovitis comprises both innate immune cells (like monocytes, DCs, and mast cells) and adaptive immune cells (like Th1, Th17, and B cells) (McInnes, 2011; Smolen et al., 2016). As described above, leptin modulates neutrophils chemotaxis, activates proliferation and phagocytosis of monocytes and/or macrophages, regulates NK cytotoxicity, induces proliferation of naïve T cells, promotes Th1 cell immune response and down-regulates Th2 cell immune response. Moreover, leptin modulates the activity of Treg cells, which are potent inhibitors of autoimmunity, thus having a potential implication in RA pathophysiology (Toussirot et al., 2015).

Several studies have found a positive correlation between serum and synovial leptin levels and RA pathology (Otero et al., 2006; Targońska-Stępniak et al., 2008; Yoshino et al., 2011; Olama et al., 2012), but there are controversial results (Anders et al., 1999; Popa et al., 2005; Hizmetli et al., 2007; Oner et al., 2015). Differing results may be due to the relatively small sample size, inconsistency of the baseline characteristics of participants (age, race, disease duration, BMI, ...), co-existence of other auto-immune diseases, employment of different methods to measure leptin levels in RA patients, or underlying patients treatments that intervene with the endocrine system. The present consensus is that leptin levels are elevated in RA patients, and serum and synovial fluid levels of leptin were associated with disease duration and parameters of RA activity (Olama et al., 2012; Lee and Bae, 2016), although large cohorts studies are necessary. Experimental animal models of arthritis had demonstrated the leptin action in joint inflammation. In particular, compared with control mice, leptin-deficient mice presented a less severe antigen-induced arthritis, decreased levels of TNF- $\alpha$ and IL-1 $\beta$ in knees synovium, and an impaired antigen-specific $\mathrm{T}$ cell proliferative response with lower
IFN- $\gamma$ and higher IL-10 production, which indicates a shift toward Th2 cell response (Busso et al., 2002). Accordingly, injection of leptin $(5 \mu \mathrm{g})$ into the knee joint of collagenimmunized mice augmented arthritis severity, accompanied by elevated synovial hyperplasia and joint damage through enhancement of Th17 cell response (Deng et al., 2012). In fact, clinical trials using a humanized anti-IL-17 monoclonal antibody added to oral disease-modifying anti-rheumatic drugs, demonstrated improved signs and symptoms of RA, indicating the therapeutic potential of IL-17-directed strategies (Genovese et al., 2010).

Since leptin modulates the immune system, as well as insulin resistance and metabolic disorders like metabolic syndrome and obesity, all RA-associated conditions, this adipokine represents an attractive therapeutic target for RA. Accordingly, reducing leptin levels in RA patients by fasting improved the clinical symptoms of the disease (Fraser et al., 1999). Amidst the possible therapeutic approaches to antagonize leptin actions in $\mathrm{RA}$, are leptin mutants with antagonist activity, and monoclonal antibodies against human LEPR or leptin itself (Tian et al., 2014). Interestingly, clinical studies evaluating the effect of drug modulators of insulin sensitivity (affected by leptin levels as described above), such as PPAR $\gamma$ agonists, are ongoing to provide new potential treatment to improve the inflammatory status and cardiovascular outcome in RA patients (Chimenti et al., 2015). Further understanding of leptin mechanisms would be of utmost importance for RA treatment.

Hence, leptin can be pointed as a link between immune tolerance, metabolic function, and autoimmunity, and leptin signaling-directed strategies could provide future innovative therapies for autoimmune disorders like RA.

\section{Systemic Lupus Erythematosus}

Systemic lupus erythematosus is a chronic autoimmune disorder of unclear etiology characterized by hyperactive $\mathrm{T}$ and $\mathrm{B}$ cells, autoantibody production, deposition of immune complex, elevated blood levels of pro-inflammatory cytokines and multisystem organ damage, encompassing from mild manifestations (non-erosive arthritis or skin rash) to lifethreatening complications (lupus nephritis, neuropsychiatric disorders, cardiovascular disorders, and metabolic syndrome). Although the pathogenesis of SLE is poorly understood, genetic, hormonal and environmental factors have been implicated in the onset of this heterogeneous disease, which predominantly affects women of childbearing age (Gatto et al., 2013; Liu and La Cava, 2014).

Several studies suggest the implication of adipokines, namely leptin, in the pathogenesis of SLE. Although some reports found no statistical association between disease activity and leptin levels (Li H.M. et al., 2016), recently, a meta-analysis of eighteen studies determined that serum/plasma leptin levels were significantly elevated in SLE patients (Lee and Song, 2018). Furthermore, leptin has been suggested as a player that affects the cardiovascular risk in SLE patients. Accordingly, leptin and HFD induced proinflammatory high-density lipoproteins and atherosclerosis in BWF1 lupus-prone mice, and leptin levels were correlated with BMI, disease activity index (SLEDAI), as well as 
insulin and CRP levels, all CVD risk factors, in SLE patients (Xu W.D.et al., 2014).

The role of leptin in SLE development has been investigated using leptin-deficient (ob/ob) mice treated with lupus-inducing agent (Lourenço et al., 2016). Leptin deficiency protected mice from the development of autoantibodies as well as renal disease, and elevated the levels of Treg cells, compared with wild-type controls. Moreover, in (NZBxNZW)F1 lupus-prone mice, leptin administration accelerated the development of autoantibodies and renal disease, while leptin antagonism delayed disease progression (Lourenço et al., 2016). At cellular level, leptin promoted Th1 responses in human CD4+ T cells and in lupusprone mice via ROR $\gamma$ transcription, whereas leptin neutralization inhibited Th17 responses in autoimmune-prone mice (Yu et al., 2013). Additionally, fasting induced hypoleptinemia or leptindeficient mice demonstrated decreased levels of Th17 and elevated levels of Treg cells (Liu et al., 2012). In SLE, apoptotic cells represent the major source of self antigens that promote and fuel autoimmune responses. Leptin promoted $\mathrm{T}$ cell survival and proliferation of autoreactive $\mathrm{T}$ cells in mice with an autoreactive $\mathrm{T}$ cell repertoire, including (NZBxNZW)F1 lupus-prone mice (Amarilyo et al., 2013). Leptin also promoted phagocytosis of apoptotic cells by macrophages in lupus-prone mice, which increase the availability of apoptotic-derived antigens to $\mathrm{T}$ cells and subsequent development of self-antigen-reactive $\mathrm{T}$ cells (Amarilyo et al., 2014).

Altogether, these data support the involvement of leptin in the development of SLE. However, further investigations are needed to fully understand the role of leptin in SLE and thus, explore this adipokine as potential therapeutic target of SLE.

\section{CONCLUSION AND FUTURE OUTLOOK}

Obesity and its comorbidities, such as T2DM, non-alcoholic fatty acid liver disease, OA and RA, reached epidemic proportions and are still rising in developing countries. Anti-obesity therapeutic options have provided only a limited long-term efficacy (lifestyle changes, physical activity, diet, and pharmacotherapies) or are not completely safe (bariatric surgery) (Zhang et al., 2014). Therefore, it has become increasingly relevant to disclose new clinical biomarkers and to develop innovative therapeutic strategies for obesity-associated pathologies and chronic inflammation.

The adipose tissue-derived factor leptin has been emerged as a key regulator of nutritional state and metabolism, as well as a modulator of immune system activation and innate-adaptive frontier; thus bridging obesity with metabolic disorders (T2DM and NAFLD) and inflammatory pathologies that affect bones and joints (OA and RA). Consequently, plasma leptin concentration could be a biological marker of the inflammatory status and the onset and evolution of pathologies associated with dysregulation of the immune system, and hereafter evaluations will be essential to establish leptin as clinical biomarker. Moreover, control of bioactive leptin levels by high-affinity leptin-binding molecules, miRNAs targeting leptin, LEPRs antagonists or monoclonal humanized antibodies against LEPR are likely to be feasible therapeutic approaches (Otvos et al., 2011). Recombinant leptin is already available for use in patients with leptin congenital deficiency while the synthetic leptin analog metreleptin has been approved for lipodystrophy treatment (Tchang et al., 2015). Importantly, the development of antibodies that could crossreact with endogenous leptin and cause an effective leptindeficient state responsible for the loss of efficacy and infection has become a significant concern (DePaoli, 2014). However, given the pleiotropic action of leptin, a systematic approach to modulate their levels and thus prevent obesity-associated disorders might be, for the moment, unavailable. Instead, strategies targeting leptin's actions precisely and in specific immune cell subpopulations, or targeting of specific receptor isoforms, could be a potential viable option to add novel therapeutic agents against immune-metabolic pathologies. It is now clear that leptin is an important regulator of metabolic status and influence inflammatory and immune responses in several diseases. Nonetheless, leptin network is complex and a lack of a full understanding of leptin's immunomodulatory mechanisms in almost all of the cells of immune system and its potential side effects are still problems that need to be figured out in drug discovery. Further insights into the pathophysiological role of leptin in the immune system and in obesity-associated disorders will be of great importance for the development of novel therapeutic approaches for these diseases.

\section{AUTHOR CONTRIBUTIONS}

VF and JP have made a substantial contribution to acquisition and analysis of data and critically revised it. VC-C, CR-F, AM, MG-G, and RG have been involved in drafting the manuscript and revising it critically for important intellectual content. OG made a substantial contribution to conception and design of the review article, drafting the manuscript, and critically revising it. All authors approved the final version to be published.

\section{FUNDING}

OG is Staff Personnel of Xunta de Galicia (Servizo Galego de Saude, SERGAS) through a research-staff stabilization contract (ISCIII/SERGAS). VF is a "Sara Borrell" Researcher funded by ISCIII and FEDER. RG is a "Miguel Servet" Researcher funded by Instituto de Salud Carlos III (ISCIII) and FEDER. OG, MG-G, and RG are members of RETICS Program, RD16/0012/0014 (RIER: Red de Investigación en Inflamación y Enfermedades Reumáticas) via Instituto de Salud Carlos III (ISCIII) and FEDER. The work of OG and JP (PIE13/00024 and PI14/00016, PI17/00409), and RG (PI16/01870 and CP15/00007) was funded by Instituto de Salud Carlos III and FEDER. OG is a beneficiary of a project funded by Research Executive Agency of the European Union in the framework of MSCA-RISE Action of the H2020 Program (Project No. 734899). The funders had no role in study design, data collection, and analysis, decision to publish, or preparation of the manuscript. 


\section{REFERENCES}

Acedo, S. C., Gambero, S., Cunha, F. G., Lorand-Metze, I., and Gambero, A. (2013). Participation of leptin in the determination of the macrophage phenotype: an additional role in adipocyte and macrophage crosstalk. In Vitro Cell. Dev. Biol. Anim. 49, 473-478. doi: 10.1007/s11626-013-9629-x

Agrawal, S., Gollapudi, S., Su, H., and Gupta, S. (2011). Leptin activates human B cells to secrete TNF- $\alpha$, IL-6, and IL-10 via JAK2/STAT3 and p38MAPK/ERK1/2 signaling pathway. J. Clin. Immunol. 31, 472-478. doi: 10.1007/s10875-0109507-1

Ajeganova, S., Andersson, M. L., and Hafström, I. (2013). Association of obesity with worse disease severity in rheumatoid arthritis as well as with comorbidities: a long-term followup from disease onset. Arthritis Care Res. 65, 78-87. doi: $10.1002 /$ acr. 21710

Al-Hassi, H. O., Bernardo, D., Murugananthan, A. U., Mann, E. R., English, N. R., Jones, A., et al. (2013). A mechanistic role for leptin in human dendritic cell migration: differences between ileum and colon in health and Crohn's disease. Mucosal Immunol. 6, 751-761. doi: 10.1038/mi.2012.113

Al-Suhaimi, E. A., and Shehzad, A. (2013). Leptin, resistin and visfatin: the missing link between endocrine metabolic disorders and immunity. Eur. J. Med. Res. 18:12. doi: 10.1186/2047-783X-18-12

Amarilyo, G., Iikuni, N., Liu, A., Matarese, G., and La Cava, A. (2014). Leptin enhances availability of apoptotic cell-derived self-antigen in systemic lupus erythematosus. PLoS One 9:e112826. doi: 10.1371/journal.pone.011 2826

Amarilyo, G., Iikuni, N., Shi, F. D., Liu, A., Matarese, G., and La Cava, A. (2013). Leptin promotes lupus T-cell autoimmunity. Clin. Immunol. 149, 530-533. doi: 10.1016/j.clim.2013.09.002

Anders, H. J., Rihl, M., Heufelder, A., Loch, O., and Schattenkirchner, M. (1999). Leptin serum levels are not correlated with disease activity in patients with rheumatoid arthritis. Metabolism 48, 745-748. doi: 10.1016/S0026-0495(99) 90174-9

Arrese, M., Cabrera, D., Kalergis, A. M., and Feldstein, A. E. (2016). Innate immunity and inflammation in NAFLD/NASH. Dig. Dis. Sci. 61, 1294-1303. doi: 10.1007/s10620-016-4049-x

Bähr, I., Goritz, V., Doberstein, H., Gesine, G., Hiller, R., Rosenstock, P., et al. (2017). Diet-induced obesity is associated with an impaired NK cell function and an increased colon cancer incidence. J. Nutr. Metab. 2017:4297025. doi: 10.1155/2017/4297025

Bao, J. P., Chen, W. P., Feng, J., Hu, P. F., Shi, Z. L., and Wu, L. D. (2010). Leptin plays a catabolic role on articular cartilage. Mol. Biol. Rep. 37, 3265-3272. doi: 10.1007/s11033-009-9911-x

Batra, A., Okur, B., Glauben, R., Erben, U., Ihbe, J., Stroh, T., et al. (2010). Leptin: a critical regulator of $\mathrm{CD}^{+}{ }^{+} \mathrm{T}$-cell polarization in vitro and in vivo. Endocrinology 151, 56-62. doi: 10.1210/en.2009-0565

Bennett, B. D., Solar, G. P., Yuan, J. Q., Mathias, J., Thomas, G. R., and Matthews, W. (1996). A role for leptin and its cognate receptor in hematopoiesis. Curr. Biol. 6, 1170-1180. doi: 10.1016/S0960-9822(02)70 684-2

Benomar, Y., Naour, N., Aubourg, A., Bailleux, V., Gertler, A., Djiane, J., et al (2006). Insulin and leptin induce Glut4 plasma membrane translocation and glucose uptake in a human neuronal cell line by a phosphatidylinositol 3-kinasedependent mechanism. Endocrinology 147, 2550-2556. doi: 10.1210/en.20051464

Bhupathiraju, S., and Hu, F. (2016). Epidemiology of obesity and diabetes and their cardiovascular complications. Circ. Res. 118, 1723-1735. doi: 10.1161/ CIRCRESAHA.115.306825

Bjorbaek, C., Uotani, S., Da Silva, B., Flier, J. S., Bjørbæk, C., Uotani, S., et al. (1997). Divergent signaling capacities of the long and short isoforms of the leptin receptor. J. Biol. Chem. 272, 32686-32695. doi: 10.1074/jbc.272.51. 32686

Boi, S. K., Buchta, C. M., Pearson, N. A., Francis, M. B., Meyerholz, D. K., Grobe, J. L., et al. (2016). Obesity alters immune and metabolic profiles: new insight from obese-resistant mice on high-fat diet. Obesity 24, 2140-2149. doi: 10.1002/ oby. 21620

Brotfain, E., Hadad, N., Shapira, Y., Avinoah, E., Zlotnik, A., Raichel, L., et al. (2015). Neutrophil functions in morbidly obese subjects. Clin. Exp. Immunol. 181, 156-163. doi: $10.1111 /$ cei.12631
Bruno, A., Conus, S., Schmid, I., and Simon, H.-U. (2005). Apoptotic pathways are inhibited by leptin receptor activation in neutrophils. J. Immunol. 174, 8090-8096. doi: 10.4049/jimmunol.174.12.8090

Busso, N., So, A., Chobaz-Peclat, V., Morard, C., Martinez-Soria, E., TalabotAyer, D., et al. (2002). Leptin signaling deficiency impairs humoral and cellular immune responses and attenuates experimental arthritis. J. Immunol. 168, 875-882. doi: 10.4049/jimmunol.168.2.875

Byrne, C. D., and Targher, G. (2015). NAFLD: a multisystem disease. J. Hepatol. 62, S47-S64. doi: 10.1016/j.jhep.2014.12.012

Caldefie-Chezet, F., Poulin, A., Tridon, A., Sion, B., and Vasson, M. P. (2001). Leptin: a potential regulator of polymorphonuclear neutrophil bactericidal action? J. Leukoc. Biol. 69, 414-418.

Caldefie-Chezet, F., Poulin, A., and Vasson, M.-P. (2003). Leptin regulates functional capacities of polymorphonuclear neutrophils. Free Radic. Res. 37, 809-814. doi: 10.1080/1071576031000097526

Cannon, J. G., Sharma, G., Sloan, G., Dimitropoulou, C., Baker, R. R., Mazzoli, A., et al. (2014). Leptin regulates CD16 expression on human monocytes in a sex-specific manner. Physiol. Rep. 2:e12177. doi: 10.14814/phy2.12177

Cao, H. (2014). Adipocytokines in obesity and metabolic disease. J. Endocrinol. 220, T47-T59. doi: 10.1530/JOE-13-0339

Cao, H., Lin, J., Chen, W., Xu, G., and Sun, C. (2016). Baseline adiponectin and leptin levels in predicting an increased risk of disease activity in rheumatoid arthritis: a meta-analysis and systematic review. Autoimmunity 49, 1-7. doi: 10.1080/08916934.2016.1230847

Carlton, E. D., Demas, G. E., and French, S. S. (2012). Leptin, a neuroendocrine mediator of immune responses, inflammation, and sickness behaviors. Horm. Behav. 62, 272-279. doi: 10.1016/j.yhbeh.2012.04.010

Cassano, S., Pucino, V., La Rocca, C., Procaccini, C., De Rosa, V., Marone, G., et al. (2014). Leptin modulates autophagy in human $\mathrm{CD} 4{ }^{+} \mathrm{CD} 25^{-}$conventional $\mathrm{T}$ cells. Metabolism 63, 1272-1279. doi: 10.1016/j.metabol.2014.06.010

Chang, S. F., Hsieh, R. Z., Huang, K. C., Chang, C. A., Chiu, F. Y., Kuo, H. C., et al. (2015). Upregulation of bone morphogenetic protein-2 synthesis and consequent collagen II expression in leptin-stimulated human chondrocytes. PLoS One 10:e0144252. doi: 10.1371/journal.pone.0144252

Chatterjee, S., Ganini, D., Tokar, E. J., Kumar, A., Das, S., Corbett, J., et al. (2013). Leptin is key to peroxynitrite-mediated oxidative stress and Kupffer cell activation in experimental non-alcoholic steatohepatitis. J. Hepatol. 58, 778-784. doi: 10.1016/j.jhep.2012.11.035

Chimenti, M. S., Triggianese, P., Conigliaro, P., Candi, E., Melino, G., and Perricone, R. (2015). The interplay between inflammation and metabolism in rheumatoid arthritis. Cell Death Dis. 6:e1887. doi: 10.1038/cddis.2015.246

Chitturi, S., Farrell, G., Frost, L., Kriketos, A., Lin, R., Fung, C., et al. (2002). Serum leptin in NASH correlates with hepatic steatosis but not fibrosis: a manifestation of lipotoxicity? Hepatology 36, 403-409. doi: 10.1053/jhep.2002.34738

Claycombe, K., King, L. E., and Fraker, P. J. (2008). A role for leptin in sustaining lymphopoiesis and myelopoiesis. Proc. Natl. Acad. Sci. U.S.A. 105, 2017-2021. doi: 10.1073/pnas.0712053105

Cohen, S., Danzaki, K., and MacIver, N. J. (2017). Nutritional effects on T-cell immunometabolism. Eur. J. Immunol. 47, 225-235. doi: 10.1002/eji.201646423

Conde, J., Gomez, R., Bianco, G., Scotece, M., Lear, P., Dieguez, C., et al. (2011a). Expanding the adipokine network in cartilage: identification and regulation of novel factors in human and murine chondrocytes. Ann. Rheum. Dis. 70, 551-559. doi: 10.1136/ard.2010.132399

Conde, J., Scotece, M., Abella, V., Gómez, R., López, V., Villar, R., et al. (2015) Identification of novel adipokines in the joint. Differential expression in healthy and osteoarthritis tissues. PLoS One 10:e0123601. doi: 10.1371/journal.pone. 0123601

Conde, J., Scotece, M., Gomez, R., Lopez, V., Gomez-Reino, J. J., and Gualillo, O. (2011b). Adipokines and osteoarthritis: novel molecules involved in the pathogenesis and progression of disease. Arthritis 2011:203901. doi: 10.1155/ $2011 / 203901$

Conde, J., Scotece, M., López, V., Abella, V., Hermida, M., Pino, J., et al. (2013). Differential expression of adipokines in infrapatellar fat pad (IPFP) and synovium of osteoarthritis patients and healthy individuals. Ann. Rheum. Dis. 73, 631-633. doi: 10.1136/annrheumdis-2013-204189

Conde, J., Scotece, M., López, V., Gómez, R., Lago, F., Pino, J., et al. (2012). Adiponectin and leptin induce VCAM-1 expression in human and murine chondrocytes. PLoS One 7:e52533. doi: 10.1371/journal.pone.0052533 
Curat, C. A., Miranville, A., Sengenès, C., Diehl, M., Tonus, C., Busse, R., et al. (2004). From blood monocytes to adipose tissue-resident macrophages: induction of diapedesis by human mature adipocytes. Diabetes Metab. Res. Rev. 53, 1285-1292. doi: 10.2337/diabetes.53.5.1285

Dayakar, A., Chandrasekaran, S., Veronica, J., and Maurya, R. (2016). Leptin induces the phagocytosis and protective immune response in Leishmania donovani infected THP-1 cell line and human PBMCs. Exp. Parasitol. 160, 54-59. doi: 10.1016/j.exppara.2015.12.002

de Boer, T. N., van Spil, W. E., Huisman, A. M., Polak, A. A., Bijlsma, J. W., Lafeber, F. P., et al. (2012). Serum adipokines in osteoarthritis; comparison with controls and relationship with local parameters of synovial inflammation and cartilage damage. Osteoarthritis Cartilage 20, 846-853. doi: 10.1016/j.joca.2012. 05.002

De Rosa, V., La Cava, A., and Matarese, G. (2017). Metabolic pressure and the breach of immunological self-tolerance. Nat. Immunol. 18, 1190-1196. doi: 10.1038/ni.3851

De Rosa, V., Procaccini, C., Calì, G., Pirozzi, G., Fontana, S., Zappacosta, S., et al. (2007). A key role of leptin in the control of regulatory $\mathrm{T}$ cell proliferation. Immunity 26, 241-255. doi: 10.1016/j.immuni.2007.01.011

DeFuria, J., Belkina, A. C., Jagannathan-Bogdan, M., Snyder-Cappione, J., Carr, J. D., Nersesova, Y. R., et al. (2013). B cells promote inflammation in obesity and type 2 diabetes through regulation of T-cell function and an inflammatory cytokine profile. Proc. Natl. Acad. Sci. U.S.A. 110, 5133-5138. doi: 10.1073/pnas. 1215840110

Deiuliis, J. A. (2016). MicroRNAs as regulators of metabolic disease: pathophysiologic significance and emerging role as biomarkers and therapeutics. Int. J. Obes. 40, 88-101. doi: 10.1038/ijo.2015.170

Deng, J., Liu, Y., Yang, M., Wang, S., Zhang, M., Wang, X., et al. (2012). Leptin exacerbates collagen-induced arthritis via enhancement of Th17 cell response. Arthritis Rheum. 64, 3564-3573. doi: 10.1002/art.34637

DePaoli, A. M. (2014). Leptin in common obesity and associated disorders of metabolism. J. Endocrinol. 223, T71-T81. doi: 10.1530/JOE-14-0258

Dib, L. H., Ortega, M. T., Melgarejo, T., and Chapes, S. K. (2016). Establishment and characterization of DB-1: a leptin receptor-deficient murine macrophage cell line. Cytotechnology 68, 921-933. doi: 10.1007/s10616-015-9843-3

Dixit, V. D., Mielenz, M., Taub, D. D., and Parvizi, N. (2003). Leptin induces growth hormone secretion from peripheral blood mononuclear cells via a protein kinase C- and nitric oxide-dependent mechanism. Endocrinology 144, 5595-5603. doi: 10.1210/en.2003-0600

do Carmo, L. S., Rogero, M. M., Paredes-Gamero, E. J., Nogueira-Pedro, A., Xavier, J. G., Cortez, M., et al. (2013). A high-fat diet increases interleukin-3 and granulocyte colony-stimulating factor production by bone marrow cells and triggers bone marrow hyperplasia and neutrophilia in Wistar rats. Exp. Biol. Med. 238, 375-384. doi: 10.1177/1535370213477976

Donath, M. Y. (2014). Targeting inflammation in the treatment of type 2 diabetes: time to start. Nat. Rev. Drug Discov. 13, 465-476. doi: 10.1038/nrd4275

Donath, M. Y., and Shoelson, S. E. (2011). Type 2 diabetes as an inflammatory disease. Nat. Rev. Immunol. 11, 98-107. doi: 10.1038/nri2925

Duarte, G. V., Oliveira, M., de, F., Cardoso, T. M., Follador, I., Silva, T. S., et al. (2013). Association between obesity measured by different parameters and severity of psoriasis. Int. J. Dermatol. 52, 177-181. doi: 10.1111/j.1365-4632. 2011.05270.x

Ducy, P., Amling, M., Takeda, S., Priemel, M., Schilling, A. F., Beil, F. T., et al. (2000). Leptin inhibits bone formation through a hypothalamic relay: a central control of bone mass. Cell 100, 197-207. doi: 10.1016/S0092-8674(00)81558-5

Dumond, H., Presle, N., Terlain, B., Mainard, D., Loeuille, D., Netter, P., et al. (2003). Evidence for a key role of leptin in osteoarthritis. Arthritis Rheum. 48, 3118-3129. doi: 10.1002/art.11303

Fan, Q., Liu, Z., Shen, C., Li, H., Ding, J., Jin, F., et al. (2018). Microarray study of gene expression profile to identify new candidate genes involved in the molecular mechanism of leptin- induced knee joint osteoarthritis in rat. Hereditas 155:4. doi: 10.1186/s41065-017-0039-z

Farooqi, I. S., Jebb, S. A., Langmack, G., Lawrence, E., Cheetham, C. H., Prentice, A. M., et al. (1999). Effects of recombinant leptin therapy in a child with congenital leptin deficiency. N. Engl. J. Med. 341, 879-884. doi: 10.1056/ NEJM199909163411204

Farooqi, I. S., Matarese, G., Lord, G. M., Keogh, J. M., Lawrence, E., Agwu, C., et al. (2002). Beneficial effects of leptin on obesity, T cell hyporesponsiveness, and neuroendocrine/metabolic dysfunction of human congenital leptin deficiency. J. Clin. Invest. 110, 1093-1103. doi: 10.1172/JCI15693

Fasshauer, M., and Blüher, M. (2015). Adipokines in health and disease. Trends Pharmacol. Sci. 36, 461-470. doi: 10.1016/j.tips.2015.04.014

Favreau, M., Menu, E., Gaublomme, D., Vanderkerken, K., Faict, S., Maes, K., et al. (2017). Leptin receptor antagonism of iNKT cell function: a novel strategy to combat multiple myeloma. Leukemia 31, 2678-2685. doi: 10.1038/leu.20 17.146

Figenschau, Y., Knutsen, G., Shahazeydi, S., Johansen, O., and Sveinbjörnsson, B. (2001). Human articular chondrocytes express functional leptin receptors. Biochem. Biophys. Res. Commun. 287, 190-197. doi: 10.1006/bbrc.2001.5543

Findlay, D. M., and Atkins, G. J. (2014). Osteoblast-chondrocyte interactions in osteoarthritis. Curr. Osteoporos. Rep. 12, 127-134. doi: 10.1007/s11914-014$0192-5$

Frasca, D., Ferracci, F., Diaz, A., Romero, M., Lechner, S., and Blomberg, B. B. (2016). Obesity decreases B cell responses in young and elderly individuals. Obesity 24, 615-625. doi: 10.1002/oby.21383

Fraser, D. A., Thoen, J., Reseland, J. E., Førre, O., and Kjeldsen-Kragh, J. (1999). Decreased CD4 ${ }^{+}$lymphocyte activation and increased interleukin-4 production in peripheral blood of rheumatoid arthritis patients after acute starvation. Clin. Rheumatol. 18, 394-401. doi: 10.1007/s100670050125

Frederich, R. C., Hamann, A., Anderson, S., Löllmann, B., Lowell, B. B., and Flier, J. S. (1995). Leptin levels reflect body lipid content in mice: evidence for diet-induced resistance to leptin action. Nat. Med. 1, 1311-1314. doi: 10.1038/ nm1295-1311

Frühbeck, G. (2006). Intracellular signalling pathways activated by leptin. Biochem. J. 393, 7-20. doi: 10.1042/BJ20051578

Fujita, Y., Fujii, T., Mimori, T., Sato, T., Nakamura, T., Iwao, H., et al. (2014). Deficient leptin signaling ameliorates systemic lupus erythematosus lesions in MRL/Mp-Fas lpr mice. J. Immunol. 192, 979-984. doi: 10.4049/jimmunol. 1301685

Fujita, Y., Yanagida, H., Mimori, T., Jin, Z. X., Sakai, T., Kawanami, T., et al. (2012). Prevention of fasting-mediated bone marrow atrophy by leptin administration. Cell. Immunol. 273, 52-58. doi: 10.1016/j.cellimm.2011.11.007

Gabay, C., Dreyer, M. G., Pellegrinelli, N., Chicheportiche, R., and Meier, C. A. (2001). Leptin directly induces the secretion of interleukin 1 receptor antagonist in human monocytes. J. Clin. Endocrinol. Metab. 86, 783-791. doi: 10.1210/jc. 86.2.783

Gaber, T., Strehl, C., and Buttgereit, F. (2017). Metabolic regulation of inflammation. Nat. Rev. Rheumatol. 13, 267-279. doi: 10.1038/nrrheum.2017.37

Gatto, M., Zen, M., Ghirardello, A., Bettio, S., Bassi, N., Iaccarino, L., et al. (2013). Emerging and critical issues in the pathogenesis of lupus. Autoimmun. Rev. 12, 523-536. doi: 10.1016/j.autrev.2012.09.003

Genovese, M. C., Van den Bosch, F., Roberson, S. A., Bojin, S., Biagini, I. M., Ryan, P., et al. (2010). LY2439821, a humanized anti-interleukin-17 monoclonal antibody, in the treatment of patients with rheumatoid arthritis: a phase I randomized, double-blind, placebo-controlled, proof-of-concept study. Arthritis Rheum. 62, 929-939. doi: 10.1002/art.27334

Gerriets, V. A., Danzaki, K., Kishton, R. J., Eisner, W., Nichols, A. G., Saucillo, D. C., et al. (2016). Leptin directly promotes T-cell glycolytic metabolism to drive effector T-cell differentiation in a mouse model of autoimmunity. Eur. J. Immunol. 46, 1970-1983. doi: 10.1002/eji.201545861

Gerriets, V. A., and MacIver, N. J. (2014). Role of T cells in malnutrition and obesity. Front. Immunol. 5:379. doi: 10.3389/fimmu.2014.00379

Gomez, R., Scotece, M., Conde, J., Gomez-Reino, J. J., Lago, F., and Gualillo, O. (2011). Adiponectin and leptin increase IL-8 production in human chondrocytes. Ann. Rheum. Dis. 70, 2052-2054. doi: 10.1136/ard.2010.145672

Griffin, T. M., Huebner, J. L., Kraus, V. B., and Guilak, F. (2009). Extreme obesity due to impaired leptin signaling in mice does not cause knee osteoarthritis. Arthritis Rheum. 60, 2935-2944. doi: 10.1002/art.24854

Grotta, M. B., Squebola-Cola, D. M., Toro, A. A., Ribeiro, M. A., Mazon, S. B., Ribeiro, J. D., et al. (2013). Obesity increases eosinophil activity in asthmatic children and adolescents. BMC Pulm. Med. 13:39. doi: 10.1186/1471-2466-1339

Gruen, M. L., Hao, M., Piston, D. W., and Hasty, A. H. (2007). Leptin requires canonical migratory signaling pathways for induction of monocyte and macrophage chemotaxis. AJP Cell Physiol. 293, C1481-C1488. doi: 10.1152/ ajpcell.00062.2007 
Gupta, S., Agrawal, S., and Gollapudi, S. (2013). Increased activation and cytokine secretion in B cells stimulated with leptin in aged humans. Immun. Ageing 10:3. doi: 10.1186/1742-4933-10-3

Gutierrez, D. A., and Hasty, A. H. (2012). Haematopoietic leptin receptor deficiency does not affect macrophage accumulation in adipose tissue or systemic insulin sensitivity. J. Endocrinol. 212, 343-351. doi: 10.1530/JOE-110338

Hizmetli, S., Kisa, M., Gokalp, N., and Bakici, M. Z. (2007). Are plasma and synovial fluid leptin levels correlated with disease activity in rheumatoid arthritis? Rheumatol. Int. 27, 335-338. doi: 10.1007/s00296-006-0264-7

Howard, J. K., Lord, G. M., Matarese, G., Vendetti, S., Ghatei, M. A., Ritter, M. A., et al. (1999). Leptin protects mice from starvation-induced lymphoid atrophy and increases thymic cellularity in ob/ob mice. J. Clin. Invest. 104, 1051-1059. doi: 10.1172/JCI6762

Huertas, A., Phan, C., Bordenave, J., Tu, L., Thuillet, R., Le Hiress, M., et al. (2016). Regulatory $\mathrm{T}$ cell dysfunction in idiopathic, heritable and connective tissue-associated pulmonary arterial hypertension. Chest 149, 1482-1493. doi: 10.1016/j.chest.2016.01.004

Huh, J. Y., Park, Y. J., Ham, M., and Kim, J. B. (2014). Crosstalk between adipocytes and immune cells in adipose tissue inflammation and metabolic dysregulation in obesity. Mol. Cells 37, 365-371. doi: 10.14348/molcells.2014.0074

Hui, W., Litherland, G. J., Elias, M. S., Kitson, G. I., Cawston, T. E., Rowan, A. D., et al. (2012). Leptin produced by joint white adipose tissue induces cartilage degradation via upregulation and activation of matrix metalloproteinases. Ann. Rheum. Dis. 71, 455-462. doi: 10.1136/annrheumdis-2011-200372

Ikejima, K., Okumura, K., Lang, T., Honda, H., Abe, W., Yamashina, S., et al. (2005). The role of leptin in progression of non-alcoholic fatty liver disease. Hepatol. Res. 33, 151-154. doi: 10.1016/j.hepres.2005.09.024

Ikejima, K., Takei, Y., Honda, H., Hirose, M., Yoshikawa, M., Zhang, Y. J., et al. (2002). Leptin receptor-mediated signaling regulates hepatic fibrogenesis and remodeling of extracellular matrix in the rat. Gastroenterology 122, 1399-1410. doi: 10.1053/gast.2002.32995

Inzaugarat, M. E., De Matteo, E., Baz, P., Lucero, D., Garcia, C. C., Ballerga, E. G., et al. (2017). New evidence for the therapeutic potential of curcumin to treat nonalcoholic fatty liver disease in humans. PLoS One 12:e0172900. doi: 10.1371/journal.pone.0172900

Jaedicke, K. M., Roythorne, A., Padget, K., Todryk, S., Preshaw, P. M., and Taylor, J. J. (2013). Leptin up-regulates TLR2 in human monocytes. J. Leukoc. Biol. 93, 561-571. doi: 10.1189/jlb.1211606

Jahn, J., Spielau, M., Brandsch, C., Stangl, G. I., Delank, K. S., Bähr, I., et al. (2015). Decreased NK cell functions in obesity can be reactivated by fat mass reduction. Obesity 23, 2233-2241. doi: 10.1002/oby.21229

Javor, E. D., Ghany, M. G., Cochran, E. K., Oral, E. A., DePaoli, A. M., Premkumar, A., et al. (2005). Leptin reverses nonalcoholic steatohepatitis in patients with severe lipodystrophy. Hepatology 41, 753-760. doi: 10.1002/hep. 20672

Jennbacken, K., Ståhlman, S., Grahnemo, L., Wiklund, O., and Fogelstrand, L. (2013). Glucose impairs B-1 cell function in diabetes. Clin. Exp. Immunol. 174, 129-138. doi: 10.1111/cei.12148

Jones, K. D., Thitiri, J., Ngari, M., and Berkley, J. A. (2014). Childhood malnutrition: toward an understanding of infection, inflammation, and antimicrobials. Food Nutr. Bull. 35(Suppl. 2), S64-S70. doi: 10.1001/jama.2009. 1266

Kakuma, T., Lee, Y., Higa, M., Wang, Z. W., Pan, W., Shimomura, I., et al. (2000). Leptin, troglitazone, and the expression of sterol regulatory element binding proteins in liver and pancreatic islets. Proc. Natl. Acad. Sci. U.S.A. 97, 8536-8541. doi: 10.1073/pnas.97.15.8536

Kalra, S. P. (2009). Central leptin gene therapy ameliorates diabetes type 1 and 2 through two independent hypothalamic relays: a benefit beyond weight and appetite regulation. Peptides 30, 1957-1963. doi: 10.1016/j.peptides.2009. 07.021

Kamada, Y., Takehara, T., and Hayashi, N. (2008). Adipocytokines and liver disease. J. Gastroenterol. 43, 811-822. doi: 10.1007/s00535-008-2 213-6

Kamp, V. M., Langereis, J. D., van Aalst, C. W., van der Linden, J. A., Ulfman, L. H., and Koenderman, L. (2013). Physiological concentrations of leptin do not affect human neutrophils. PLoS One 8:e73170. doi: 10.1371/journal.pone.007 3170
Kato, H., Ueki, S., Kamada, R., Kihara, J., Yamauchi, Y., Suzuki, T., et al. (2011). Leptin has a priming effect on eotaxin-induced human eosinophil chemotaxis. Int. Arch. Allergy Immunol. 155, 335-344. doi: 10.1159/000321195

Kavak, K. S., Teter, B. E., Hagemeier, J., Zakalik, K., Weinstock-Guttman, B., Edwards, K., et al. (2015). Higher weight in adolescence and young adulthood is associated with an earlier age at multiple sclerosis onset. Mult. Scler. 21, 858-865. doi: 10.1177/1352458514555787

Kiguchi, N., Maeda, T., Kobayashi, Y., Fukazawa, Y., and Kishioka, S. (2009). Leptin enhances CC-chemokine ligand expression in cultured murine macrophage. Biochem. Biophys. Res. Commun. 384, 311-315. doi: 10.1016/j.bbrc.2009.04.121

Kim, S. Y., Lim, J. H., Choi, S. W., Kim, M., Kim, S. T., Kim, M. S., et al. (2010). Preferential effects of leptin on CD4 T cells in central and peripheral immune system are critically linked to the expression of leptin receptor. Biochem. Biophys. Res. Commun. 394, 562-568. doi: 10.1016/j.bbrc.2010.03.019

Klöting, N., and Blüher, M. (2014). Adipocyte dysfunction, inflammation and metabolic syndrome. Rev. Endocr. Metab. Disord. 15, 277-287. doi: 10.1007/ s11154-014-9301-0

Koskinen, A., Vuolteenaho, K., Nieminen, R., Moilanen, T., and Moilanen, E. (2011). Leptin enhances MMP-1, MMP-3 and MMP-13 production in human osteoarthritic cartilage and correlates with MMP-1 and MMP-3 in synovial fluid from OA patients. Clin. Exp. Rheumatol. 29, 57-64.

Koskinen-kolasa, A., Vuolteenaho, K., Korhonen, R., Moilanen, T., and Moilanen, E. (2016). Catabolic and proinflammatory effects of leptin in chondrocytes are regulated by suppressor of cytokine signaling-3. Arthritis Res. Ther. 215, 1-13. doi: 10.1186/s13075-016-1112-0

Kulkarni, R. N., Wang, Z. L., Wang, R. M., Hurley, J. D., Smith, D. M., Ghatei, M. A., et al. (1997). Leptin rapidly suppresses insulin release from insulinoma cells, rat and human islets and, in vivo, in mice. J. Clin. Invest. 100, 2729-2736. doi: 10.1172/JCI119818

Lam, Q. L., Liu, S., Cao, X., and Lu, L. (2006). Involvement of leptin signaling in the survival and maturation of bone marrow-derived dendritic cells. Eur. J. Immunol. 36, 3118-3130. doi: 10.1002/eji.200636602

Lam, Q. L., Wang, S., Ko, O. K., Kincade, P. W., and Lu, L. (2010). Leptin signaling maintains B-cell homeostasis via induction of Bcl-2 and Cyclin D1. Proc. Natl. Acad. Sci. U.S.A. 107, 13812-13817. doi: 10.1073/pnas.1004185107

Lamas, A., Lopez, E., Carrio, R., and Lopez, D. M. (2016). Adipocyte and leptin accumulation in tumor-induced thymic involution. Int. J. Mol. Med. 37, 133138. doi: 10.3892/ijmm.2015.2392

Lamas, B., Goncalves-Mendes, N., Nachat-Kappes, R., Rossary, A., CaldefieChezet, F., Vasson, M. P., et al. (2013). Leptin modulates dose-dependently the metabolic and cytolytic activities of NK-92 cells. J. Cell. Physiol. 228, 1202-1209. doi: $10.1002 /$ jcp. 24273

Laue, T., Wrann, C. D., Hoffmann-Castendiek, B., Pietsch, D., Hübner, L., and Kielstein, H. (2015). Altered NK cell function in obese healthy humans. BMC Obes. 2:1. doi: 10.1186/s40608-014-0033-1

Lebovitz, H. E. (2003). The relationship of obesity to the metabolic syndrome. Int. J. Clin. Pract. Suppl. 134, 18-27.

Lee, Y., Yu, X., Gonzales, F., Mangelsdorf, D. J., Wang, M.-Y., Richardson, C., et al. (2002). PPAR alpha is necessary for the lipopenic action of hyperleptinemia on white adipose and liver tissue. Proc. Natl. Acad. Sci. U.S.A. 99, 11848-11853. doi: 10.1073/pnas.182420899

Lee, Y. H., and Bae, S. C. (2016). Circulating leptin level in rheumatoid arthritis and its correlation with disease activity: a meta-analysis. Z. Rheumatol. 75, 1021-1027. doi: 10.1007/s00393-016-0050-1

Lee, Y. H., and Song, G. G. (2018). Association between circulating leptin levels and systemic lupus erythematosus: an updated meta-analysis. Lupus 27, 428-435. doi: $10.1177 / 0961203317725587$

Li, H. M., Zhang, T. P., Leng, R. X., Li, X. P., Li, X. M., Liu, H. R., et al. (2016). Emerging role of adipokines in systemic lupus erythematosus. Immunol. Res. 64, 820-830. doi: 10.1007/s12026-016-8808-8

Li, K., Wei, L., Huang, Y., Wu, Y., Su, M., Pang, X., et al. (2016). Leptin promotes breast cancer cell migration and invasion via IL-18 expression and secretion. Int. J. Oncol. 48, 2479-2487. doi: 10.3892/ijo.2016.3483

Licinio, J., Caglayan, S., Ozata, M., Yildiz, B. O., de Miranda, P. B., O’Kirwan, F., et al. (2004). Phenotypic effects of leptin replacement on morbid obesity, diabetes mellitus, hypogonadism, and behavior in leptin-deficient adults. Proc. Natl. Acad. Sci. U.S.A. 101, 4531-4536. doi: 10.1073/pnas.030876 7101 
Liu, A., and La Cava, A. (2014). Epigenetic dysregulation in systemic lupus erythematosus. Autoimmunity 47, 215-219. doi: 10.3109/08916934.2013. 844794

Liu, Y., Yu, Y., Matarese, G., and La Cava, A. (2012). Cutting edge: fastinginduced hypoleptinemia expands functional regulatory $\mathrm{T}$ cells in systemic lupus erythematosus. J. Immunol. 188, 2070-2073. doi: 10.4049/jimmunol.1102835

Lo, C., Lam, Q. L., Yang, M., Ko, K.-H., Sun, L., Ma, R., et al. (2009). Leptin signaling protects NK cells from apoptosis during development in mouse bone marrow. Cell. Mol. Immunol. 6, 353-360. doi: 10.1038/cmi.2009.46

Loeser, R. F., Goldring, S. R., Scanzello, C. R., and Goldring, M. B. (2012). Osteoarthritis: a disease of the joint as an organ. Arthritis Rheum. 64, 1697-1707. doi: 10.1002/art.34453

Lord, G. M., Matarese, G., Howard, J. K., Baker, R. J., Bloom, S. R., and Lechler, R. I. (1998). Leptin modulates the T-cell immune response and reverses starvationinduced immunosuppression. Nature 394, 897-901. doi: 10.1038/29795

Lord, G. M., Matarese, G., Howard, J. K., Bloom, S. R., and Lechler, R. I. (2002). Leptin inhibits the anti-CD3-driven proliferation of peripheral blood $\mathrm{T}$ cells but enhances the production of proinflammatory cytokines. J. Leukoc. Biol. 72, 330-338.

Lourenço, E. V., Liu, A., Matarese, G., and La Cava, A. (2016). Leptin promotes systemic lupus erythematosus by increasing autoantibody production and inhibiting immune regulation. Proc. Natl. Acad. Sci. U.S.A. 113, 10637-10642. doi: $10.1073 /$ pnas. 1607101113

Luan, B., Goodarzi, M. O., Phillips, N. G., Guo, X., Chen, Y. D., Yao, J., et al. (2014). Leptin-mediated increases in catecholamine signaling reduce adipose tissue inflammation via activation of macrophage HDAC4. Cell Metab. 19, 1058-1065. doi: 10.1016/j.cmet.2014.03.024

Ma, L., Li, D., Sookha, M. R., Fang, M., Guan, Y., Sun, X., et al. (2015). Elevated serum leptin levels in patients with systemic lupus erythematosus. Pharmazie 70, 720-723. doi: 10.1691/ph.2015.5649

MacIver, N. J., Michalek, R. D., and Rathmell, J. C. (2013). Metabolic regulation of T lymphocytes. Annu. Rev. Immunol. 31, 259-283. doi: 10.1146/annurevimmunol-032712-095956

Maingrette, F., and Renier, G. (2003). Leptin increases lipoprotein lipase secretion by macrophages: involvement of oxidative stress and protein kinase C. Diabetes Metab. Res. Rev. 52, 2121-2128. doi: 10.2337/diabetes.52.8. 2121

Mancuso, P. (2004). Leptin augments alveolar macrophage leukotriene synthesis by increasing phospholipase activity and enhancing group IVC iPLA2 (cPLA2gamma) protein expression. AJP Lung Cell. Mol. Physiol. 287, L497-L502. doi: 10.1152/ajplung.00010.2004

Mancuso, P., Myers, M. G., Goel, D., Serezani, C. H., O’Brien, E., Goldberg, J., et al. (2012). Ablation of leptin receptor-mediated ERK activation impairs host defense against Gram-negative pneumonia. J. Immunol. 189, 867-875. doi: 10.4049/jimmunol.1200465

Margiotta, D., Navarini, L., Vadacca, M., Basta, F., Vullo, M., Pignataro, F., et al. (2016). Relationship between leptin and regulatory $\mathrm{T}$ cells in systemic lupus erythematosus?: preliminary results. Eur. Rev. Med. Pharmacol. Sci. 20, 636-641.

Marques-Rocha, J. L., Samblas, M., Milagro, F. I., Bressan, J., Martínez, J. A., and Marti, A. (2015). Noncoding RNAs, cytokines, and inflammation-related diseases. FASEB J. 29, 3595-3611. doi: 10.1096/fj.14-260323

Martínez-Carrillo, B. E., Jarillo-Luna, R. A., Campos-Rodríguez, R., ValdésRamos, R., and Rivera-Aguilar, V. (2015). Effect of diet and exercise on the peripheral immune system in young Balb/c mice. Biomed Res. Int. 2015:458470. doi: 10.1155/2015/458470

Martín-Romero, C., Santos-Alvarez, J., Goberna, R., and Sánchez-Margalet, V. (2000). Human leptin enhances activation and proliferation of human circulating monocytes. Cell. Immunol. 199, 15-24. doi: 10.1006/cimm.1999. 1490

Matarese, G. (2000). Leptin and the immune system: how nutritional status influences the immune response. Eur. Cytokine Netw. 11, 7-13. doi: 10.1519/ JSC.0b013e3181bab493

Matarese, G., Procaccini, C., De Rosa, V., Horvath, T. L., and La Cava, A. (2010). Regulatory T cells in obesity: the leptin connection. Trends Mol. Med. 16, 247-256. doi: 10.1016/j.molmed.2010.04.002

Mathis, D., and Shoelson, S. E. (2011). Immunometabolism: an emerging frontier. Nat. Rev. Immunol. 11, 81-83. doi: 10.1038/nri2922
Mattioli, B., Giordani, L., Quaranta, M. G., and Viora, M. (2009). Leptin exerts an anti-apoptotic effect on human dendritic cells via the PI3K-Akt signaling pathway. FEBS Lett. 583, 1102-1106. doi: 10.1016/j.febslet.2009. 02.029

Mattioli, B., Straface, E., Matarrese, P., Quaranta, M. G., Giordani, L., Malorni, W., et al. (2008). Leptin as an immunological adjuvant: enhanced migratory and $\mathrm{CD}^{+} \mathrm{T}$ cell stimulatory capacity of human dendritic cells exposed to leptin. FASEB J. 22, 2012-2022. doi: 10.1096/fj.07-098095

Maurya, R., Bhattacharya, P., Ismail, N., Dagur, P. K., Joshi, A. B., Razdan, K., et al. (2016). Differential role of leptin as an immunomodulator in controlling visceral Leishmaniasis in normal and leptin-deficient mice. Am. J. Trop. Med. Hyg. 95, 109-119. doi: 10.4269/ajtmh.15-0804

McInnes, I. (2011). The pathogenesis of rheumatoid arthritis. N. Engl. J. Med. 365, 2205-2219. doi: 10.7748/phc2011.11.21.9.29.c8797

Meier, C. A., Chicheportiche, R., Dreyer, M., and Dayer, J. M. (2003). IP-10, but not RANTES, is upregulated by leptin in monocytic cells. Cytokine 21, 43-47. doi: 10.1016/S1043-4666(02)00491-X

Mittendorfer, B., Horowitz, J. F., DePaoli, A. M., McCamish, M. A., Patterson, B. W., and Klein, S. (2011). Recombinant human leptin treatment does not improve insulin action in obese subjects with type 2 diabetes. Diabetes Metab. Res. Rev. 60, 1474-1477. doi: 10.2337/db10-1302

Montecucco, F., Bianchi, G., Gnerre, P., Bertolotto, M., Dallegri, F., and Ottonello, L. (2006). Induction of neutrophil chemotaxis by leptin: crucial role for p38 and Src kinases. Ann. N. Y. Acad. Sci. 1069, 463-471. doi: 10.1196/ annals. 1351.045

Moon, H.-S., Matarese, G., Brennan, A. M., Chamberland, J. P., Liu, X., Fiorenza, C. G., et al. (2011). Efficacy of metreleptin in obese patients with type 2 diabetes: cellular and molecular pathways underlying leptin tolerance. Diabetes Metab. Res. Rev. 60, 1647-1656. doi: 10.2337/db10-1791

Moraes-Vieira, P. M., Larocca, R. A., Bassi, E. J., Peron, J. P., Andrade-Oliveira, V., Wasinski, F., et al. (2014). Leptin deficiency impairs maturation of dendritic cells and enhances induction of regulatory T and Th17 cells. Eur. J. Immunol. 44, 794-806. doi: 10.1002/eji.201343592

Morteza, A., Nakhjavani, M., Asgarani, F., Ghaneei, A., Esteghamati, A., and Mirmiranpour, H. (2013). The lost correlation between leptin and CRP in type 2 diabetes. Eur. Cytokine Netw. 24, 53-59. doi: 10.1684/ecn.2013. 0329

Morton, G. J., Gelling, R. W., Niswender, K. D., Morrison, C. D., Rhodes, C. J., and Schwartz, M. W. (2005). Leptin regulates insulin sensitivity via phosphatidylinositol-3-OH kinase signaling in mediobasal hypothalamic neurons. Cell Metab. 2, 411-420. doi: 10.1016/j.cmet.2005.1 0.009

Münzberg, H., and Morrison, C. D. (2015). Structure, production and signaling of leptin. Metabolism 64, 13-23. doi: 10.1016/j.metabol.2014.09.010

Mutabaruka, M.-S., Aoulad Aissa, M., Delalandre, A., Lavigne, M., and Lajeunesse, D. (2010). Local leptin production in osteoarthritis subchondral osteoblasts may be responsible for their abnormal phenotypic expression. Arthritis Res. Ther. 12:R20. doi: 10.1186/ar2925

Najib, S., and Sánchez-Margalet, V. (2002). Human leptin promotes survival of human circulating blood monocytes prone to apoptosis by activation of $\mathrm{p} 42 / 44$ MAPK pathway. Cell. Immunol. 220, 143-149. doi: 10.1016/S0008-8749(03) 00027-3

Nakamura, Y., Sanematsu, K., Ohta, R., Shirosaki, S., Koyano, K., Nonaka, K., et al. (2008). Diurnal variation of human sweet taste recognition thresholds is correlated with plasma leptin levels. Diabetes Metab. Res. Rev. 57, 2661-2665. doi: $10.2337 / \mathrm{db} 07-1103$

Namkoong, C., Kim, M. S., Jang, P. G., Han, S. M., Park, H. S., Koh, E. H., et al. (2005). Enhanced hypothalamic AMP-activated protein kinase activity contributes to hyperphagia in diabetic rats. Diabetes Metab. Res. Rev. 54, 63-68. doi: $10.2337 /$ diabetes.54.1.63

Nave, H., Mueller, G., Siegmund, B., Jacobs, R., Stroh, T., Schueler, U., et al. (2008). Resistance of Janus kinase-2 dependent leptin signaling in natural killer (NK) Cells: a novel mechanism of NK cell dysfunction in diet-induced obesity. Endocrinology 149, 3370-3378. doi: 10.1210/en.2007-1516

Naylor, C., Burgess, S., Madan, R., Buonomo, E., Razzaq, K., Ralston, K., et al. (2014). Leptin receptor mutation results in defective neutrophil recruitment to the colon during Entamoeba histolytica infection. mBio 5:e02046-14. doi: $10.1128 / \mathrm{mBio} .02046-14$ 
Nikolajczyk, B. S. (2010). B cells as under-appreciated mediators of non-autoimmune inflammatory disease. Cytokine 50, 234-242. doi: 10.1016/j.cyto.2010. 02.022

Nugent, M. (2016). MicroRNAs: exploring new horizons in osteoarthritis. Osteoarthritis Cartilage 24, 573-580. doi: 10.1016/j.joca.2015.10.018

Olama, S. M., Senna, M. K., and Elarman, M. (2012). Synovial/Serum leptin ratio in rheumatoid arthritis: the association with activity and erosion. Rheumatol. Int. 32, 683-690. doi: 10.1007/s00296-010-1698-5

Oner, S., Volkan, O., Oner, C., Mengi, A., Direskeneli, H., and Da, T. (2015). Serum leptin levels do not correlate with disease activity in rheumatoid arthritis. Acta Reumatol. Port. 40, 50-54.

Oral, E. A., Simha, V., Ruiz, E., Andewelt, A., Premkumar, A., Snell, P., et al. (2002). Leptin-replacement therapy for lipodystrophy. N. Engl. J. Med. 346, 570-578. doi: 10.1056/NEJMoa012437

Orlova, E. G., and Shirshev, S. V. (2014). Role of leptin and ghrelin in induction of differentiation of IL-17-producing and T-regulatory cells. Bull. Exp. Biol. Med. 156, 819-822. doi: 10.1007/s10517-014-2459-3

O'Rourke, L., Yeaman, S. J., and Shepherd, P. R. (2001). Insulin and leptin acutely regulate cholesterol ester metabolism in macrophages by novel signaling pathways. Diabetes Metab. Res. Rev. 50, 955-961. doi: 10.2337/diabetes.50. 5.955

Otero, M., Gomez Reino, J. J., and Gualillo, O. (2003). Synergistic induction of nitric oxide synthase type II: in vitro effect of leptin and interferon-gamma in human chondrocytes and ATDC5 chondrogenic cells. Arthritis Rheum. 48, 404-409. doi: 10.1002/art.10811

Otero, M., Lago, R., Gomez, R., Lago, F., Dieguez, C., Gómez-Reino, J. J., et al. (2006). Changes in plasma levels of fat-derived hormones adiponectin, leptin, resistin and visfatin in patients with rheumatoid arthritis. Ann. Rheum. Dis. 65, 1198-1201. doi: 10.1136/ard.2005.046540

Otero, M., Lago, R., Gómez, R., Lago, F., Gomez-Reino, J. J., and Gualillo, O. (2007). Phosphatidylinositol 3-kinase, MEK-1 and p38 mediate leptin/interferon-gamma synergistic NOS type II induction in chondrocytes. Life Sci. 81, 1452-1460. doi: 10.1016/j.lfs.2007.09.007

Otero, M., Lago, R., Lago, F., Reino, J. J., and Gualillo, O. (2005). Signalling pathway involved in nitric oxide synthase type II activation in chondrocytes: synergistic effect of leptin with interleukin-1. Arthritis Res. Ther. 7, R581-R591. doi: 10.1186/ar1708

Otvos, L., Shao, W.-H., Vanniasinghe, A. S., Amon, M. A., Csilla Holub, M., Kovalszky, I., et al. (2011). Toward understanding the role of leptin and leptin receptor antagonism in preclinical models of rheumatoid arthritis. Peptides 32, 1567-1574. doi: 10.1016/j.peptides.2011.06.015

Ozata, M., Uçkaya, G., Beyhan, Z., and Ozdemir, I. C. (1999). Plasma leptin levels in male patients with idiopathic central diabetes insipidus. J. Endocrinol. Invest. 22, 451-454. doi: 10.1007/BF03343589

Pearson, M. J., Herndler-Brandstetter, D., Tariq, M. A., Nicholson, T. A., Philp, A. M., Smith, H. L., et al. (2017). IL-6 secretion in osteoarthritis patients is mediated by chondrocyte-synovial fibroblast cross-talk and is enhanced by obesity. Sci. Rep. 7:3451. doi: 10.1038/s41598-017-03759-w

Pelleymounter, M. A., Cullen, M. J., Baker, M. B., Hecht, R., Winters, D., Boone, T., et al. (1995). Effects of the obese gene product on body weight regulation in ob/ob mice. Science 269, 540-543. doi: 10.1126/science.7624776

Pérez-Pérez, A., Vilariño-García, T., Fernández-Riejos, P., Martín-González, J., Segura-Egea, J. J., and Sánchez-Margalet, V. (2017). Role of leptin as a link between metabolism and the immune system. Cytokine Growth Factor Rev. 35, 71-84. doi: 10.1016/j.cytogfr.2017.03.001

Petersen, K. F., Oral, E. A., Dufour, S., Befroy, D., Ariyan, C., Yu, C., et al. (2002). Leptin reverses insulin resistance and hepatic steatosis in patients with severe lipodystrophy. J. Clin. Invest. 109, 1345-1350. doi: 10.1172/JCI20021 5001

Polyzos, S. A., Kountouras, J., and Mantzoros, C. S. (2015). Leptin in nonalcoholic fatty liver disease: a narrative review. Metabolism 64, 60-78. doi: 10.1016/j. metabol.2014.10.012

Popa, C., Netea, M. G., Radstake, T. R. D., van Riel, P. L., Barrera, P., and van der Meer, J. W. (2005). Markers of inflammation are negatively correlated with serum leptin in rheumatoid arthritis. Ann. Rheum. Dis. 64, 1195-1198. doi: 10.1136/ard.2004.032243

Procaccini, C., De Rosa, V., Galgani, M., Carbone, F., Cassano, S., Greco, D., et al. (2012). Leptin-induced mTOR activation defines a specific molecular and transcriptional signature controlling $\mathrm{CD} 4+$ effector $\mathrm{T}$ cell responses. J. Immunol. 189, 2941-2953. doi: 10.4049/jimmunol.1200935

Procaccini, C., La Rocca, C., Carbone, F., De Rosa, V., Galgani, M., and Matarese, G. (2017). Leptin as immune mediator: interaction between neuroendocrine and immune system. Dev. Comp. Immunol. 66, 120-129. doi: 10.1016/j.dci.2016.06.006

Rahmati, M., Mobasheri, A., and Mozafari, M. (2016). Inflammatory mediators in osteoarthritis: a critical review of the state-of-the-art, current prospects, and future challenges. Bone 85, 81-90. doi: 10.1016/j.bone.2016.01.019

Ramirez, O., and Garza, K. M. (2014). Leptin deficiency in vivo enhances the ability of splenic dendritic cells to activate $\mathrm{T}$ cells. Int. Immunol. 26, 627-636. doi: 10.1093/intimm/dxu067

Reis, B. S., Lee, K., Fanok, M. H., Mascaraque, C., Amoury, M., Cohn, L. B., et al. (2015). Leptin receptor signaling in T cells is required for Th17 differentiation. J. Immunol. 194, 5253-5260. doi: 10.4049/jimmunol.1402996

Rodríguez, L., Graniel, J., and Ortiz, R. (2007). Effect of leptin on activation and cytokine synthesis in peripheral blood lymphocytes of malnourished infected children. Clin. Exp. Immunol. 148, 478-485. doi: 10.1111/j.1365-2249.2007. 03361.x

Rosenbaum, M., and Leibel, R. L. (2014). Role of leptin in energy homeostasis in humans. J. Endocrinol. 223, T83-T96. doi: 10.1530/JOE-140358

Sanchez-Margalet, V., and Martin-Romero, C. (2001). Human leptin signaling in human peripheral blood mononuclear cells: activation of the JAKSTAT pathway. Cell. Immunol. 211, 30-36. doi: 10.1006/cimm.2001. 1815

Sánchez-Pozo, C., Rodriguez-Baño, J., Domínguez-Castellano, A., Muniain, M. A., Goberna, R., and Sánchez-Margalet, V. (2003). Leptin stimulates the oxidative burst in control monocytes but attenuates the oxidative burst in monocytes from HIV-infected patients. Clin. Exp. Immunol. 134, 464-469. doi: 10.1111/ j.1365-2249.2003.02321.x

Santos-Alvarez, J., Goberna, R., and Sánchez-Margalet, V. (1999). Human leptin stimulates proliferation and activation of human circulating monocytes. Cell. Immunol. 194, 6-11. doi: 10.1006/cimm.1999.1490

Saucillo, D. C., Gerriets, V. A., Sheng, J., Rathmell, J. C., Maciver, N. J., and Stedman, S. W. (2014). Leptin metabolically licenses T cells for activation to link nutrition and immunity. J. Immunol. 192, 136-144. doi: 10.4049/jimmunol. 1301158

Saxena, N. K., Ikeda, K., Rockey, D. C., and Friedman, S. L. (2002). Leptin in hepatic fibrosis: evidence for increased collagen production in stellate cells and lean littermates of ob/ob mice. Hepatology 35, 762-771. doi: 10.1053/jhep.2002. 32029

Schultze, S. M., Hemmings, B. A., Niessen, M., and Tschopp, O. (2012). PI3K/AKT, MAPK and AMPK signalling: protein kinases in glucose homeostasis. Expert Rev. Mol. Med. 14:el. doi: 10.1017/S1462399411002109

Scotece, M., Conde, J., López, V., Lago, F., Pino, J., Gómez-Reino, J. J., et al. (2014). Adiponectin and leptin: new targets in inflammation. Basic Clin. Pharmacol. Toxicol. 114, 97-102. doi: 10.1111/bcpt.12109

Scotece, M., Pérez, T., Conde, J., Abella, V., López, V., Pino, J., et al. (2017). Adipokines induce pro-inflammatory factors in activated $\mathrm{Cd} 4+\mathrm{T}$ cells from osteoarthritis patient. J. Orthop. Res. 35, 1299-1303. doi: 10.1002/jor.2 3377

Seol, D., McCabe, D. J., Choe, H., Zheng, H., Yu, Y., Jang, K., et al. (2012). Chondrogenic progenitor cells respond to cartilage injury. Arthritis Rheum. 64, 3626-3637. doi: 10.1002/art.34613

Silha, J. V., Krsek, M., Skrha, J. V., Sucharda, P., Nyomba, B. L., and Murphy, L. J. (2003). Plasma resistin, adiponectin and leptin levels in lean and obese subjects: correlations with insulin resistence. Eur. J. Endocrinol. 149, 331-335. doi: $10.1530 /$ eje. 0.1490331

Smolen, J. S., Aletaha, D., and McInnes, I. B. (2016). Rheumatoid arthritis. Lancet 388, 2023-2038. doi: 10.1016/S0140-6736(16)30173-8

Sun, Z., Dragon, S., Becker, A., and Gounni, A. S. (2013). Leptin inhibits neutrophil apoptosis in children via ERK/NF-кB-dependent pathways. PLoS One 8:e55249. doi: 10.1371/journal.pone.0055249

Suzukawa, M., Nagase, H., Ogahara, I., Han, K., Tashimo, H., Shibui, A., et al. (2011). Leptin enhances survival and induces migration, degranulation, and cytokine synthesis of human basophils. J. Immunol. 186, 5254-5260. doi: 10.4049/jimmunol.1004054 
Tacke, F., and Yoneyama, H. (2013). From NAFLD to NASH to fibrosis to HCC: role of dendritic cell populations in the liver. Hepatology 58, 494-496. doi: 10.1002/hep.26405

Tajiri, K., and Shimizu, Y. (2012). Role of NKT cells in the pathogenesis of NAFLD. Int. J. Hepatol. 2012:850836. doi: 10.1155/2012/850836

Tanaka, M., Suganami, T., Kim-Saijo, M., Toda, C., Tsuiji, M., Ochi, K., et al. (2011). Role of central leptin signaling in the starvation-induced alteration of B-cell development. J. Neurosci. 31, 8373-8380. doi: 10.1523/JNEUROSCI.6562-10. 2011

Targońska-Stępniak, B., Majdan, M., and Dryglewska, M. (2008). Leptin serum levels in rheumatoid arthritis patients: relation to disease duration and activity. Rheumatol. Int. 28, 585-591. doi: 10.1007/s00296-007-0480-9

Taylor, A. K., Cao, W., Vora, K. P., De La Cruz, J., Shieh, W. J., Zaki, S. R., et al. (2013). Protein energy malnutrition decreases immunity and increases susceptibility to influenza infection in mice. J. Infect. Dis. 207, 501-510. doi: 10.1093/infdis/jis527

Tchang, B. G., Shukla, A. P., and Aronne, L. J. (2015). Metreleptin and generalized lipodystrophy and evolving therapeutic perspectives. Expert Opin. Biol. Ther. 15, 1061-1075. doi: 10.1517/14712598.2015.1052789

Tian, G., Liang, J.-N., Wang, Z.-Y., and Zhou, D. (2014). Emerging role of leptin in rheumatoid arthritis. Clin. Exp. Immunol. 177, 557-570. doi: 10.1111/cei. 12372

Tian, Z., Chen, Y., and Gao, B. (2013). Natural killer cells in liver disease. Hepatology 57, 1654-1662. doi: 10.1002/hep.26115

Tian, Z., Sun, R., Wei, H., and Gao, B. (2002). Impaired natural killer (NK) cell activity in leptin receptor deficient mice: leptin as a critical regulator in NK cell development and activation. Biochem. Biophys. Res. Commun. 298, 297-302. doi: 10.1016/S0006-291X(02)02462-2

Tilg, H., and Moschen, A. R. (2006). Adipocytokines: mediators linking adipose tissue, inflammation and immunity. Nat. Rev. Immunol. 6, 772-783. doi: 10. 1038/nri1937

Tiniakos, D. G., Vos, M. B., and Brunt, E. M. (2010). Nonalcoholic fatty liver disease: pathology and pathogenesis. Annu. Rev. Pathol. Mech. Dis. 5, 145-171. doi: 10.1146/annurev-pathol-121808-102132

Toussirot, É., Michel, F., Binda, D., and Dumoulin, G. (2015). The role of leptin in the pathophysiology of rheumatoid arthritis. Life Sci. 140, 29-36. doi: 10.1016/ j.lfs.2015.05.001

Tsiotra, P. C., Boutati, E., Dimitriadis, G., and Raptis, S. A. (2013). High insulin and leptin increase resistin and inflammatory cytokine production from human mononuclear cells. Biomed Res. Int. 2013:487081. doi: 10.1155/2013/48 7081

Tsiotra, P. C., Pappa, V., Raptis, S. A., and Tsigos, C. (2000). Expression of the long and short leptin receptor isoforms in peripheral blood mononuclear cells: implications for leptin's actions. Metabolism 49, 1537-1541. doi: 10.1053/meta. 2000.18519

Tsochatzis, E. A., Papatheodoridis, G. V., and Archimandritis, A. J. (2009). Adipokines in nonalcoholic steatohepatitis: from pathogenesis to implications in diagnosis and therapy. Mediators Inflamm. 2009:831670. doi: 10.1155/2009/ 831670

Ubags, N. D., Vernooy, J. H., Burg, E., Hayes, C., Bement, J., Dilli, E., et al. (2014). The role of leptin in the development of pulmonary neutrophilia in infection and Acute Lung Injury. Crit. Care Med. 42, 143-151. doi: 10.1097/ CCM.0000000000000048

Vestweber, D. (2015). How leukocytes cross the vascular endothelium. Nat. Rev. Immunol. 15, 692-704. doi: 10.1038/nri3908

Vieira-Potter, V. J. (2014). Inflammation and macrophage modulation in adipose tissues. Cell. Microbiol. 16, 1484-1492. doi: 10.1111/cmi.12336

Voloshyna, I., Mounessa, J., Carsons, S. E., and Reiss, A. B. (2016). Effect of inhibition of interleukin-12/23 by ustekinumab on the expression of leptin and leptin receptor in human THP-1 macrophages. Clin. Exp. Dermatol. 41, 308-311. doi: 10.1111/ced.12699

Vuolteenaho, K., Koskinen, A., Kukkonen, M., Nieminen, R., Päivärinta, U., Moilanen, T., et al. (2009). Leptin enhances synthesis of proinflammatory mediators in human osteoarthritic cartilage-mediator role of NO in leptininduced PGE2, IL-6, and IL-8 production. Mediators Inflamm. 2009:345838. doi: $10.1155 / 2009 / 345838$

Wagner, N. M., Brandhorst, G., Czepluch, F., Lankeit, M., Eberle, C., Herzberg, S., et al. (2013). Circulating regulatory $\mathrm{T}$ cells are reduced in obesity and may identify subjects at increased metabolic and cardiovascular risk. Obesity 21, 461-468. doi: 10.1002/oby.20087

Wang, J., Leclercq, I., Brymora, J. M., Xu, N., Ramezani-Moghadam, M., London, R. M., et al. (2009). Kupffer cells mediate leptin-induced liver fibrosis. Gastroenterology 137, 713-723. doi: 10.1053/j.gastro.2009.04.011

Wang, S., Baidoo, S. E., Liu, Y., Zhu, C., Tian, J., Ma, J., et al. (2013). T cellderived leptin contributes to increased frequency of $\mathrm{T}$ helper type 17 cells in female patients with Hashimoto's thyroiditis. Clin. Exp. Immunol. 171, 63-68. doi: 10.1111/j.1365-2249.2012.04670.x

Wang, X., Qiao, Y., Yang, L., Song, S., Han, Y., Tian, Y., et al. (2017). Leptin levels in patients with systemic lupus erythematosus inversely correlate with regulatory T cell frequency. Lupus 26, 1401-1406. doi: 10.1177/096120331770 3497

Winer, D. A., Winer, S., Shen, L., Wadia, P. P., Yantha, J., Paltser, G., et al. (2011). B cells promote insulin resistance through modulation of $\mathrm{T}$ cells and production of pathogenic IgG antibodies. Nat. Med. 17, 610-617. doi: 10.1038/nm. 2353

Wolsk, E., Mygind, H., Grondahl, T. S., Pedersen, B. K., and van Hall, G. (2011). The role of leptin in human lipid and glucose metabolism: the effects of acute recombinant human leptin infusion in young healthy males. Am. J. Clin. Nutr. 94, 1533-1544. doi: 10.3945/ajcn.111.012260

Wong, C. K., Cheung, P. F., and Lam, C. W. (2007). Leptin-mediated cytokine release and migration of eosinophils: implications for immunopathophysiology of allergic inflammation. Eur. J. Immunol. 37, 2337-2348. doi: 10.1002/eji. 200636866

Wrann, C. D., Laue, T., Hübner, L., Kuhlmann, S., Jacobs, R., Goudeva, L., et al. (2012). Short-term and long-term leptin exposure differentially affect human natural killer cell immune functions. Am. J. Physiol. Endocrinol. Metab. 302, E108-E116. doi: 10.1152/ajpendo.00057.2011

Xu, R., Huang, H., Zhang, Z., and Wang, F.-S. (2014). The role of neutrophils in the development of liver diseases. Cell. Mol. Immunol. 11, 224-231. doi: 10.1038/cmi.2014.2

Xu, W. D., Zhang, M., Zhang, Y. J., Liu, S. S., Pan, H. F., and Ye, D. Q. (2014). Association between leptin and systemic lupus erythematosus. Rheumatol. Int. 34, 559-563. doi: 10.1007/s00296-013-2774-4

Yadav, A., Jyoti, P., Jain, S. K., and Bhattacharjee, J. (2011). Correlation of adiponectin and leptin with insulin resistance: a pilot study in healthy north Indian population. Indian J. Clin. Biochem. 26, 193-196. doi: 10.1007/s12291011-0119-1

Yoshino, T., Kusunoki, N., Tanaka, N., Kaneko, K., Kusunoki, Y., Endo, H., et al. (2011). Elevated serum levels of resistin, leptin, and adiponectin are associated with C-reactive protein and also other clinical conditions in rheumatoid arthritis. Intern. Med. 50, 269-275. doi: 10.2169/internalmedicine.50.4306

Yu, Y., Liu, Y., Shi, F.-D., Zou, H., Matarese, G., and La Cava, A. (2013). Cutting edge: leptin-induced ROR $\gamma \mathrm{t}$ expression in $\mathrm{CD} 4+\mathrm{T}$ cells promotes Th17 responses in systemic lupus erythematosus. J. Immunol. 190, 3054-3058. doi: $10.4049 /$ jimmunol.1203275

Zarkesh-Esfahani, H., Pockley, A. G., Wu, Z., Hellewell, P. G., Weetman, A. P., and Ross, R. J. (2004). Leptin indirectly activates human neutrophils via induction of TNF- $\alpha$. J. Immunol. 172, 1809-1814. doi: 10.4049/jimmunol.172.3.1809

Zhang, Y., Liu, J., Yao, J., Ji, G., Qian, L., Wang, J., et al. (2014). Obesity: pathophysiology and intervention. Nutrients 6, 5153-5183. doi: 10.3390/ nu6115153

Zhang, Y., Proenca, R., Maffei, M., Barone, M., Leopold, L., and Friedman, J. M. (1994). Positional cloning of the mouse obese gene and its human homologue. Nature 372, 425-432. doi: 10.1038/372425a0

Zhao, F.-Q., and Keating, A. (2007). Functional properties and genomics of glucose transporters. Curr. Genomics 8, 113-128. doi: 10.2174/13892020778036 8187

Zhao, X., Dong, Y., Zhang, J., Li, D., Hu, G., Yao, J., et al. (2016). Leptin changes differentiation fate and induces senescence in chondrogenic progenitor cells. Cell Death Dis. 7:e2188. doi: 10.1038/cddis.2016.68

Zhao, Y., Sun, R., You, L., Gao, C., and Tian, Z. (2003). Expression of leptin receptors and response to leptin stimulation of human natural killer cell lines. Biochem. Biophys. Res. Commun. 300, 247-252. doi: 10.1016/S0006-291X(02) 02838-3

Zheng, C., Yang, Q., Cao, J., Xie, N., Liu, K., Shou, P., et al. (2016). Local proliferation initiates macrophage accumulation in adipose 
tissue during obesity. Cell Death Dis. 7:e2167. doi: 10.1038/cddis.20 16.54

Zhou, B., Li, H., and Shi, J. (2017). miR-27 inhibits the NF-кB signaling pathway by targeting leptin in osteoarthritic chondrocytes. Int. J. Mol. Med. 40, 523-530. doi: 10.3892/ijmm.2017.3021

Zhou, Y., and Rui, L. (2014). Leptin signaling and leptin resistance. Front. Med. 7, 207-222. doi: 10.1007/s11684-013-0263-5

Zhou, Y., Yu, X., Chen, H., Sjöberg, S., Roux, J., Zhang, L., et al. (2015). Leptin deficiency shifts mast cells toward anti-inflammatory actions and protects mice from obesity and diabetes by polarizing M2 macrophages. Cell Metab. 22, 1045-1058. doi: 10.1016/j.cmet.2015.09.013
Conflict of Interest Statement: The authors declare that the research was conducted in the absence of any commercial or financial relationships that could be construed as a potential conflict of interest.

Copyright (c) 2018 Francisco, Pino, Campos-Cabaleiro, Ruiz-Fernández, Mera, Gonzalez-Gay, Gómez and Gualillo. This is an open-access article distributed under the terms of the Creative Commons Attribution License (CC BY). The use, distribution or reproduction in other forums is permitted, provided the original author(s) and the copyright owner are credited and that the original publication in this journal is cited, in accordance with accepted academic practice. No use, distribution or reproduction is permitted which does not comply with these terms. 